\title{
Maese Nicolás Francés: su obra y estilo. Estado de la cuestión.
}

\author{
Carmen Rebollo Gutiérrez \\ Becaria Fundación del Patrimonio Histórico de Castilla y León
}

\begin{abstract}
RESUMEN. Nicolás Francés, autor de una de las mayores empresas artísticas de finales de la Edad Media: la obra mural que ocupa los muros del claustro catedralicio leonés, se da a conocer a través de los investigadores que se han involucrado en el estudio de su personalidad artística. Desde este artículo se propone una revisión crítica de esta historiografía, punto de arranque para un posterior trabajo de investigación de su obra mural. La importancia que tuvo la obra del pintor Nicolás Francés en la pintura leonesa de la décimoquinta centuria justifica el interés de una producción artística, compleja por su riqueza formal e iconográfica, así como por ser uno de los pocos representantes del gótico internacional en el ámbito castellanoleonés.

Palabras clave: Nicolás Francés, pintura gótica leonesa, siglo XV, historiografía.

ABSTRACT. Nicolás Francés, craftsman of one the biggest artistic job at the end of Middle Ages in Spain: the mural painting on the walls in the cathedral cloister from León, is known by the research workers who have token an interest in the study about his artistic personality. From this article we propose a critical revision of this historiography, starting point to a next investigation about his mural work. The weight of Nicolás Francés' painting in the fifteenth century in León justifies the interest, no only in an artistic production, complex because of his formal and iconographic richness, but also to be one of few international stile example in the scenery castellanoleonés.

Key words: Nicolás Francés, painting gothic in Léon, fifteenth century, historiography.
\end{abstract}

La adquisición por parte del Estado de una tabla atribuida a Nicolás Francés para su exposición en la recién inaugurada sede del Museo Provincial de León vuelve a poner de manifiesto la gran valía de este artista y la calidad que con su labor aportó al panorama pictórico leonés a finales de la Edad Media, a la vez que se evidencian importantes aspectos aún por esclarecer en relación a su personalidad artística ${ }^{1}$.

\footnotetext{
${ }^{1}$ Quiero dar las gracias al director del Museo Provincial de León D. Luis Grau Lobo por su colaboración a la hora de facilitar la correspondiente imagen de esta
}

Pocos artistas pertenecientes al ámbito leonés de finales de la Edad Media aparecen tan pródigamente citados en la documentación como Maestre Nicolás Francés. Gran parte de su obra se desarrolló en el entorno de la sede leonesa, lo que facilitó la conservación de numerosas referencias documentales al respecto de su obra y a la relación que mantuvo con su cliente más importante, el cabildo catedralicio,

obra, así como por la atención prestada y el interés mostrado en el tema aquí tratado. 
como tendremos ocasión de describir a lo largo de este trabajo.

Varios e importantes expertos se han ocupado de este polifacético artista, sin que con ello se haya conseguido concluir todo lo que su personalísima labor consiguió reflejar en las artes leonesas del siglo XV.

Con este estudio se pretende hacer una valoración crítica de lo que hasta ahora se ha dado a conocer acerca de este virtuoso maestro que facilite una actualización tal como el tema merece.

\section{EL DESCUBRIMIENTO DEL ARTISTA}

Demetrio de los Ríos sería el primero en dar a conocer el nombre de este pintor, cuando con ocasión de la restauración de la catedral leonesa a finales del siglo XIX y la publicación de su obra La Catedral de León, ya diera cuenta de Maestre Nicolás como artista de "diestro pincel" muy frecuentemente citado en los Libros de cuentas de Fábrica así como en los de Rentas de la Catedral $^{2}$.

En un principio y basándose exclusivamente en esas referencias documentales, únicamente le atribuye el malogrado Juicio Final en el interior del muro a los pies del templo catedralicio que el autor considera la obra maestra del artista, de cuya destrucción a causa de criterios demasiados pudorosos a principios del siglo XIX se lamenta ${ }^{3}$, y las ya entonces deterioradas pinturas del claustro que se entretiene en describir para finalizar haciendo una llamada de atención sobre su estado y sugerir su restauración ${ }^{4}$.

${ }^{2}$ D. De Los Ríos y SERRANO, La Catedral de León, T. I y II, Madrid, 1895.

${ }^{3}$ Idem, T. I, p.123-125.

${ }^{4}$ Unas décadas más tarde, en los años veinte, el arquitecto Juan Crisóstomo Torbado realizaría una intervención que a primera vista parece seguir las pautas propuestas por D. DE LOS RíOS, Op. cit., T. I, p. 129: “...reproduciendo, sin adición alguna, las borra-
Cuando en el Tomo II vuelve a detenerse en la figura de Maestre Nicolás, a modo de recapitulación, incluye noticias de otras labores desempeñadas para la Catedral como el pintar cartones ${ }^{5}$, colocar él mismo las vidrieras de la Capilla de San Sebastián ${ }^{6}$, e incluso otros trabajos de menor consideración como pintar las armas del rey ${ }^{7}$, limpiar el trono de la Virgen, dorar los órganos o pintar un pendón ${ }^{8}$.

Es a raíz de todas estas tareas más rutinarias por lo que Demetrio de los Ríos consideraría que se trataba de un artista muy estimado por el cabildo, que sirviendo a la Catedral de forma continuada se habría convertido en un asalariado fijo de esa ca$\mathrm{sa}^{9}$.

\section{LOS PRIMEROS AVANCES}

En los primeros años del siglo XX, con ocasión del encargo de la realización de los Catálogos Monumentales de España del por entonces Ministerio de Instrucción Pública y Bellas Artes, Manuel Gómez Moreno rastreó durante los años 1906-1908 la provincia de León, aunque la primera edición del catálogo data de $1925^{10}$.

das líneas...", silueteando las figuras tal y como hoy se conservan, actuación que ha suscitado posturas desiguales en otros autores como iremos exponiendo llegado el caso.

${ }^{5}$ Idem, T. II, p. 216, “...dibusase las vidrieras é pintase la Claustra...".

${ }^{6}$ Idem, T. II, p. 217, “...nueve piezas de vidrios...”.

${ }^{7}$ Idem, "...pintó las armas del rey que se pusieron con las Obispo Fortín Velásquez. Que Dios Haya, é pintó más la mitra del obispote..."

${ }^{8}$ Idem.

${ }^{9}$ Apoya esta valoración en que la casa que habitaba el artista y que el autor considera de las mejores basándose en descripciones documentales en las cuales también constaba la renta, era propiedad de la Catedral, lo que le permitía una digna situación prueba de la estimación en que se le tenía. Idem, T. II, p. 217.

${ }^{10}$ M. GÓMEZ MoReno, Catálogo Monumental de España. Provincia de León, T. I y II, Madrid, 1925. 
Entre ambas fechas media la publicación de un artículo del mismo autor con el objetivo concreto de definir un conjunto de obras escultóricas, con gran influencia nórdica, que anteceden a la irrupción de las exitosas creaciones de Juan de Colonia y Anequín Egas, corrigiendo la idea de considerar a éstos personajes como indiscutibles pioneros en la irrupción en Castilla de dichas tendencias ${ }^{11}$.

El artículo en cuestión revela las relaciones formales que existen entre ciertas empresas artísticas importantes y otras obras de menor alcance dentro de un conjunto, en el que destaca la labor escultórica de la Capilla del Contador Saldaña en el convento de Clarisas de Tordesillas, en la provincia de Valladolid, en ella se vería involucrado, al lado de los grandes importadores de esa influencia europea, un artista por entonces mal conocido de nombre $\mathrm{Ni}$ colás ${ }^{12}$.

El autor descubre la semejanza entre la pintura de las puertas del retablo de la capilla del Contador y el friso pintado por debajo del arrocabe de la capilla mayor con unas obras que durante la tarea de elaboración del mencionado catálogo había tenido ocasión de admirar en la Catedral y San Isidoro, ambos en la capital leonesa. Observa cierto parentesco de todas ellas con la miniatura de las Horas del Duque de Berry, consideración que se refuerza al asemejarlo también con la obra de Broderlam en la Cartuja de Dijon ${ }^{13}$.

${ }^{11}$ M.GómEZ MORENO, “¿Joosken de Utrech, arquitecto y escultor?", Boletín de la Sociedad Castellana de Excursiones, T. V, 1911, pp. 63-66.

${ }^{12}$ Idem, p. 65.

${ }^{13}$ Idem. Sobre todo se referiría a los restos del retablo original del altar mayor de la Catedral que forman parte del actual y a una miniatura de un cantoral perteneciente a la biblioteca de San Isidoro, a ambas haremos la referencia oportuna más adelante.
En el mismo artículo hace referencia a un artista llamado Nicolao, maestro de la Catedral de León, a quien considera francés como consecuencia de la detallada lectura que hace en lo que a este artista se refiere en la Crónica del Passo Honroso de don Suero de Quiñones también citado por el Conde de Viñaza ${ }^{14}$. Igualmente y remitiéndose al mismo texto le atribuye labor de escultor a causa de la realización del famoso faraute que allí se describe y le involucra en cierta manera en la autoría de la imaginería del retablo de Tordesillas, teniendo en cuenta la naturaleza mixta del mismo, cuyo interior representa el tema de la Pasión mediante la composición de pequeños grupos, no por cuanto la considera atribuida directamente a él, pero sí a artistas con quienes tendría algún tipo de contacto ${ }^{15}$, argumentando que

-

${ }^{14}$ Idem, p. 66. El relato de la hazaña fue encargado al mismo notario de la familia Quiñones, Pero Rodríguez de Lena, quien sería observador directo de los hechos, por lo que la crónica sería escrita al tiempo que se celebraban las justas o poco después. A partir de Sánchez Cantón serán recurrentes las referencias a esta obra en todo lo que en ella alude al Maestro Nicolás Francés. Su autoría del retablo de la catedral, la minuciosa descripción del faraute que pintó para el passo, la narración de su cuidadoso asentamiento, todo son noticias preciosas que sirven para dar luz a la personalidad del pintor. Existen varios manuscritos: en El Escorial, en la Biblioteca Nacional, así como en al Academia de la Historia. Su primera publicación se llevó a cabo por F. JUAN DE PINEDA en Libro del paso honroso...copilado de un antiguo libro de mano, Salamanca, 1588, reeditado en Madrid, 1783 y en Nueva York, 1903. Sin embargo la relación antigua no está impresa íntegramente aunque se dieran amplios extractos por J. DE ALLENDE en la obra Relaciones de Solemnidades y fiestas públicas en España, Madrid, 1903, T. 1, pp.3 y ss. Para más información acerca de la obra consultar la edición de A. LABANDEIRA FERNÁNDEZ, El passo honroso de Suero de Quiñones, según el cronista Pedro Rodríguez de Lena, Madrid, 1977.

${ }^{15}$ La discusión se centra entre considerarla como obra oriunda de países del norte y por lo tanto de importación, o bien la posibilidad de que se tratase de una obra realizada en la Península por algún autor formado en los Países Bajos. De la primera opinión sería E. BERTAUX, "La peinture et la sculpture espagnoles au XIVe et au XVe siècle jusqu'au temps des rois Catholiques", Histoire de l'art, T.III, París, 1908, 2ª 
aparecen citados en los mismos lugares y en un mismo periodo de tiempo, como sucede con Guillem de Rouen ${ }^{16}$ y Joosken de Utrecht ambos con encargos en la Catedral de León ${ }^{17}$. En este momento aun no identificaba al pintor del retablo de Tordesillas con el maestro leonés.

Volviendo a su labor del Catálogo, la minuciosa búsqueda de Gómez Moreno, como ya advertimos, le llevó hasta la rica biblioteca de San Isidoro. Entre sus excepcionales fondos, un libro de coro contiene

parte, p. 771, donde se defiende la semejanza con la labor de Jacques de Baerze en el retablo de la cartuja de Dijon. Más prudente se muestran en tan categórica afirmación G. WEISE, Spanische plastik aus sieben Jahrhunderten, T. I, Reutlingen, 1935-1939, p. 45 al que le recuerda el estilo de Sluter y los modelos escultóricos del retablo de San Salvador de Haekendover. Ambos reconocen que se trata de una tipología muy generalizada en los Países Bajos durante todo el siglo XV y consecuentemente muy exportado, en lo que coinciden M. GÓMEZ MORENO, "¿Joosken de...", quien encuentra relación entre el último ejemplo y las estatuas monumentales de la capilla y T. MÜLLER, Sculture in the Netherlands, Germany, France, Spain (1400-1500), Suffolk-London, 1966, p. 52.

${ }^{16}$ Guillem de Rouen o Rohan, en adelante se utilizará la forma según aparezca trascrita en la obra que se esté comentando. El compromiso de este artista con la obra en la capilla del Contador se documenta por la inscripción en una lápida que se encontraba en el exterior de la capilla y que lamentablemente ya no se conserva, su texto rezaba: "Aquí yace Maestre Guillen de Rohan maestro de la iglesia de León et aparejador de esta capilla que finó a VII días de diciembre año de mil e CCC e XXX et un años". La lápida en cuestión es primeramente referenciada en la obra publicada por A. Cean Bermúdez y E. Llaguno Y Amirola, Noticias de los arquitectos y arquitectura de España, Madrid, 1829, p. 102; también se hace eco de ella J. M. QUADRADO, España. Sus monumentos y artes. Su naturaleza e historia. Valladolid, Palencia y Zamora, Barcelona, 1885, p. 241, en su obra se narra la curiosa noticia que el retablo de la capilla habría sido el altar portátil de Pedro I el Cruel, que él no comparte. El último historiador que la cita de primera mano es M. GÓMEZ MORENO, "¿Joosken de...", p. 64.

${ }^{17}$ Será a este maestro a quien responsabiliza principalmente de la autoría de las más significativas obras de las que trata el estudio, Joosken que hispanizado en Jusquín aparece documentado en León, M. GóMEZ MORENO, “iJoosken de...", p. 66. una escena de la Navidad que el autor atribuyó al pintor del retablo de la Catedral. La silueta de una $\mathrm{N}$, que parece observarse en la chimenea del pesebre, ayuda a corroborar esa teoría al entenderse que el artista quiso dejar su inicial como prueba de su autoría $^{18}$.

Ya en lo que se refiere a su obra en la Catedral leonesa el pintor Maestre Nicolás aparece comprometido en los diseños de las vidrieras, de tal manera que en el catálogo se le atribuyen de forma concreta las rosas de algunas capillas, refiriéndose concretamente a las alegorías ${ }^{19}$. Más contundente se muestra al adjudicarle la vidriera del tímpano de la puerta del claustro con la imagen de la Virgen del Dado, que describe como grisalla con toques amarillos y rojos, en la que junto a la Virgen en pie con el Niño en brazos aparecen unos personajes jugando a los dados, en alusión al milagro que narra, un obispo orante y el escudo del obispo don Pedro Cabeza de Vaca, quien ocupara la sede leonesa durante los años de 1440 a $1459^{20}$.

Por lo que se refiere a la pintura, Gómez Moreno tras alabar la colección catedralicia, hace destacada referencia a Maestre Nicolás, artífice del retablo del altar mayor, dibujante de vidrieras, artífice de los murales de alguna de las capillas, de los del claustro y de la pintura del Juicio Final $^{21}$.

En estas páginas se comienza describiendo las obras murales, primeramente se le atribuyen las que hay en la antigua capilla de San Fabián y San Sebastián, documentadas y datadas en 1459, y posterior-

\footnotetext{
${ }^{18}$ La N en cuestión viene acompañada de un rasgo que simula la abreviatura -us tan frecuente en al escritura de la época. M. Gómez MORENO, Catálogo Monumental ..., T. I, p. 205 y T. II, lámina 223.

19 Idem, T. I, p. 267.

${ }^{20}$ Idem, T. I, p. 268.

21 Idem, T: I, p. 270
} 
mente las pinturas del claustro. Basándose en los documentos, si bien reconoce en ellas la colaboración de varias manos, considera que la labor realizada entre los años $1460 \mathrm{y}$ 1468 pertenece a Maestre Nicolás. El autor aprecia en estas pinturas una tendencia italiana sin perspectiva y la utilización de tamaño jerárquico ${ }^{22}$.

En 1925, coincidiendo con la fecha de publicación de la primera edición del mencionado Catálogo monumental de la provincia de León, se llevó a cabo la restauración de las pinturas del claustro por Juan Crisóstomo Torbado; la intervención del arquitecto aparece comentada en la obra ${ }^{23}$.

Acerca de la pintura sobra tabla, no sólo se hace un seguimiento del itinerario seguido por los distintos paneles a partir del desmonte del retablo mayor en el siglo XVIII y su recuperación ${ }^{24}$; además de su descripción y un breve detenimiento en su técnica, el autor se adentra en los aspectos estilísticos y formales buscando relaciones e influencias que expliquen la personalidad artística de Maestre Nicolás. De este modo encuentra coincidencias con trecentistas

-

${ }^{22}$ Idem, T. I, p. 273 y T. II, lámina 324.

${ }^{23}$ El autor del Catálogo celebra que con la actuación se intensificara la visibilidad de las imágenes a la vez que lamenta que se perdieran los retoques finales con que el artista perfeccionara la obra, o que al menos no se realizara un pertinente reportaje fotográfico que sirviera de referencia de los estados anteriores. Idem, T. I, p. 273-274.

${ }^{24}$ El retablo se desmontó para colocar uno barroco de Gavilán Tomé, que a su vez se desmontó para volver a restituir lo que se pudo recuperar de las tablas de Nicolás Francés que habían sido repartidas por humildes parroquias como las que se recuperaron de Trobajo del Camino o La Aldea de la Valdoncina. La obra del siglo XVIII se encuentra en la iglesia de los franciscanos en la capital leonesa y le preside la misma Virgen que originariamente pertenecía al retablo del XV de Nicolás Francés. E. DÍAZ JIMÉNEZ, El retablo de la Catedral de León, Madrid, 1907; J. M. PRADOS GARCíA, "El retablo mayor del siglo XVIII de la Catedral de León", Archivo Español de Arte, n. 220, 1982, pp. 329350. italianos de la talla de Gaddi, con prerrenacentistas en cuanto a la concepción individual de las figuras como Altichiero di Zevio y su colaborador Jacopo Avanzi, refinados artistas del arte cortesano como Gentile y Pisanello, o también aspectos en afinidad con lo flamenco, como sucede con la obra de los hermanos Limbourg ${ }^{25}$. Destaca en el artista la captación de un personalísimo naturalismo poco accesible en su época. $Y$ aunque el autor le considera de carácter más arcaico que Nicolás Florentino, parece que su fuerte personalidad suplía ese primitivismo ${ }^{26}$.

Gracias a las averiguaciones de Gómez Moreno la figura de Nicolás Francés iba esclareciéndose, su personalidad artística emergía gracias a las apreciaciones de estos primeros estudiosos que con una gran intuición iban definiendo unos rasgos que permitían valorar y atribuir con seguridad sus obras. No todo fueron pasos acertados. A la vez se estaba investigando la labor del otro Nicolás en la catedral de Salamanca, aquel al que hemos hecho referencia como el Florentino. Célebre fue la polémica que se creó con la identificación de Nicolás, el maestro de la catedral leonesa, con el artista italiano, que obstinadamente defendía Juan Eloy Díaz Jiménez ${ }^{27}$, y no pasaría de ser más que anecdótica si no fuera porque la refutación que al caso se hizo por parte de Raimundo Rodríguez dio a conocer importantes referencias documentales que serían

-

${ }^{25}$ Como anotamos oportunamente, ya se había decantado por este parentesco en el artículo M. GÓMEZ MORENO, “¿Joosken de Utrecht...", p. 65.

${ }^{26}$ M. Gómez Moreno, Cátalogo..., T. I, p. 274-277 y T. II, láminas 370-376.

${ }^{27}$ Primeramente expone esta teoría en J. E. DíAZ JIMÉNEZ, "El pintor Nicolás Florentino", Anales del Instituto General y Técnico de Valencia, 1923, y la mantiene en "Nuevos documentos sobre Maestre Nicolás", Boletín de la Biblioteca Menéndez Pelayo, n. enero-marzo, 1928, pp. 26-33. 
soporte trascendental para posteriores avances en el estudio del artista leonés ${ }^{28}$.

\section{DESARROLLO Y PRIMERAS DISCRE- PANCIAS}

Por la misma época, durante los primeros años del siglo $\mathrm{XX}$, se encontraría realizando su labor de sondeo de obras a lo largo de toda la geografía peninsular el historiador norteamericano Chandler Rathfon Post, un trabajo ingente para la realización de su obra $A$ history of Spanish painting, publicada entre los años 1930 y $1966^{29}$. La obra, organizada en capítulos y publicada por volúmenes, se ocupa del estudio de la pintura del gótico internacional en Castilla en su volumen III.

-

${ }^{28}$ La contestación a las afirmaciones de Díaz Jiménez se difundieron desde las humildes páginas de un periódico local, R. RODRÍGUEZ, “El pintor Maestre Nicolás y otros maestros", Diario de León, 8 de enero de 1923; “El pintor Maestre Nicolás y otros maestros. Maestre Nicolás no es el Nicolás pintor de la catedral de Valencia", Diario de León, 17 de febrero de 1923 y "Maestre Nicolás", Diario de León, 19 de febrero de 1923. Más adelante tuvo ocasión de presentar un amplia muestra de sus sondeos en el Archivo de la Catedral de León en "Extracto de la Actas capitulares de la catedral de León", Archivos leoneses, n. 12, 1952, pp. 95-109; n.18, 1955, pp. 151-166; n.19, 1956, pp.183190; n.20, 1956, pp. 123-148; n. 22, 1957, pp. 147-175; n. 23, 1958, pp. $183-192 ;$ n. 24,1958 , pp. 317-368; n. 31, 1962 , pp. 111-146 y 308-324. Con respecto a esta cuestión cabe destacar el interés que se tomó $\mathrm{M}$. GóMEZ MORENO, Catálogo..., T: I, p. 270, en diferenciar a Maestre Nicolás, al que ya se refiere como Nicolás Francés, de Nicolás Florentino, para ello Gómez Moreno recurrió a la obra dedicada a Nicolás Francés de F. J. Sánchez Cantón, estudios que aún no estarían realizados en la época en la que trabajaba en el rastreo de obras para el Catálogo, pero que sí serían anteriores a la publicación del mismo y que con buen criterio Gómez Moreno incluiría en la pertinente revisión, de ellos nos ocuparemos más adelante.

${ }^{29}$ CH. R. POST, A history of Spanish painting, Cambridge, 1930-1966. En la misma obra se hace una referencia cronológica que sitúa al autor realizando este estudio poco después de la restauración de las pinturas del claustro, llevada a cabo por el arquitecto Juan Crisóstomo Torbado en los años veinte, p. 263.
En el capítulo XLI del mencionado volumen, con título "Nicolás Francés y su círculo", el autor analiza meticulosamente la obra y las características formales del artista leonés ${ }^{30}$. Post destaca sobre todo la influencia italiana que domina la producción pictórica castellanoleonesa en general y la obra de Maese Nicolás en particular. Pese a conocer la referencia que se hace al artista en la Crónica del Passo Honroso de Pero Rodríguez de Lena que Gómez Moreno sería el primero en advertir, en la que aparece como Nicolás Francés ${ }^{31}$, la hispanización que advierte en sus obras le inclina a insinuar que más que su origen personal, su apellido podría indicar simplemente el origen familiar ${ }^{32}$.

El recorrido que hace por las principales obras que le son atribuidas con seguridad al pintor, le sirve al autor para justificar el evidente italianismo que según él se plasma en las pinturas en base a sus rasgos formales e iconográficos ${ }^{33}$.

${ }^{30}$ Idem, "Nicolás Francés and his circle", Chapter XLI, V. III, Cambridge, 1930, pp. 261-296.

${ }^{31}$ M. Gómez MORENO, “¿Joosken de Utrecht...”, p. 65. Esta observación sería muy apreciada por Francisco Javier Sánchez Cantón a la hora de definir la procedencia francesa del artista. Los estudios y conclusiones tanto de Chandler R. Post como de Sánchez Cantón acerca de Nicolás Francés se simultanearon en estos años de tal forma que ambos estaban al corriente de las indagaciones que se estaban realizando por uno y otro, unas veces coincidiendo y otras discrepando como tendremos ocasión de reflejar.

${ }^{32}$ CH. R. POST, Op. cit., p. 261.

${ }^{33}$ Las obras de las que principalmente se sirve para apoyar su teoría son primeramente el retablo mayor de la Catedral leonesa, pero sobre todo se remite a las pinturas murales del claustro. Pese a que se refiere incorrectamente a ellas como frescos y que en ningún momento se entretiene en considerar la técnica empleada, será el primer estudioso que repara en sus rasgos formales de una manera más detenida. Luego lo argumenta con la miniatura de San Isidoro, las pinturas murales de la capilla de San Fabián y San Sebastián, actualmente de Santa Teresa, y las de la girola, incluso iconográficamente remite los atributos de las alegorías de las vidrieras, que con reticencias se 
Sin determinar de forma definitiva cual es la vía por la que el artista asimilaría esa tendencia, Post insinúa una justificación en la relación entre Nicolás Francés y los que fueron sus clientes y promotores en la principal empresa para la que realizó sus servicios de forma más constante, la catedral de León. Obispos de procedencia italiana como Juan de Pontibus (1434-1437) o Antonio de Veneris (1464-1469) tendrían muy presente una moda que fomentaría en el pintor el uso de recursos italianizantes ${ }^{34}$.

La descripción de las escenas sirve al autor para indagar contactos concretos, y mostrar los modelos y semejanzas precisos, que en último término se encuentran principalmente en Gentile Fabriano y su gótico internacional, tanto en lo que se refiere a composición como a tonalidad ${ }^{35}$.

Su típico internacionalismo se manifiesta en diferentes aspectos, su tendencia a la monumentalidad giottesca en los ropajes y drapeados, a la delicadeza y exquisitez cercana a Pisanello ${ }^{36}$, y al afán narrativo para lo que se ayuda de la abundancia de

le atribuyen, a modelos italianos, Idem, pp. 269. Posteriormente lo justifica en las obras no documentadas fuera de la capital leonesa, el retablo de la capilla del Contador Saldaña en el convento de Santa Clara en Tordesillas y el retablo de San Francisco, que inmediatamente después pasaría a formar parte de los fondos del Museo del Prado. Idem, pp. 261-286.

${ }^{34}$ Post ve plausible la idea de identificar con Antonio de Veneris con la efigie del obispo representado en la escena mural que representa el Santo Entierro en el claustro, teniendo incluso que proponer una cronología de las pinturas que antepusiera la realización de los episodios de la Pasión y Muerte de Jesús a la ejecución de los que tratan su infancia y vida de la Virgen e hiciera posible el retrato de este obispo en vida de Nicolás Francés, Idem, p. 268. Apoya esta propuesta acerca del italianismo que en 1452 en época del prelado Don Pedro Cabeza de Vaca, se comisione al artista un viaje a Salamanca para conocer de primera mano la obra del Juicio Final que el italiano Dello Delli está realizando en la catedral. Idem, p. 270.

\footnotetext{
${ }^{35}$ Idem, p. 269.

${ }^{36}$ Idem, p. 272.
}

detalles y representación de estampas de género secundarias y a menor escala, que frecuentemente incluye en la escena princi$\mathrm{pal}^{37}$, además de una riqueza excepcional en lo que a tipos de efigies, personajes, atuendos, actitudes y posturas se refiere que provocan que los retablos catalanes de la época resulten monótonos en comparación ${ }^{38}$.

Con esto manifiesta su desacuerdo con los que atribuyen al artista una formación francesa y una afinidad con el arte pictórico flamenco, parisino o borgonón. Las semejanzas que relacionaban a Nicolás Francés con la miniatura de la corte del Duque de Berry que propondrá Sánchez Cantón, o las coincidencias con los paneles borgoñones de Melchior Broderlam que propugnaban Emile Bertaux y August L. Mayer son de esta forma totalmente con-

-

${ }^{37}$ Son muchos los ejemplos de este tipo de escenas marginales a pequeña escala que recrea el autor, puesto que son muy frecuentes a lo largo de toda la obra de Nicolás Francés. En el retablo mayor de la Catedral, en el panel que representa la traslación del cuerpo de Santiago, se observa a un peregrino que arroja una piedra al crucero que Post interpreta como tradición y que podemos relacionar con la costumbre de tirar una piedra a la base de la Cruz del Ferro en la cumbre del Monte Irago entre León y Santiago al paso del Camino por el Bierzo; en la misma obra en el panel de la visita de Alfonso III a San Froilán, en el ángulo inferior izquierdo una pareja se muestra en actitud poco decorosa, Idem, p. 272.

${ }^{38}$ Baste de ejemplo el juglar con pandereta que aparece en la escena de la visita de Alfonso III a San Froilán ya referida antes Idem, p. 274, o todos los paneles de santos que compondrían las entrecalles del magnífico retablo original, parte de los que conformaron la silla episcopal y que hoy se exhiben en el museo diocesano y que muestran una versatilidad admirable Idem, p. 263. Con relación a estas representaciones de santos vuelve a tratar en $\mathrm{CH}$. R. POST Op. cit, T. IV, Appendix, (1933), p. 656, donde da cuenta de algunos paneles en muy mal estado localizados en el taller de Juan Torbado entre los que reconoce una Santa Escolástica, y que con mucha probabilidad podría tratarse de la tabla recientemente adquirida por el Museo Provincial de León. 
tradichas ${ }^{39}$, concediendo a cualquiera de estas aproximaciones una justificación en virtud de su internacionalismo, capaz de reflejar ciertos valores del arte europeo consustancial a toda obra considerada dentro del gótico internacional ${ }^{40}$.

La vía por la que Nicolás Francés accede a todo ese bagaje formal e iconográfico sería, no tanto de origen, puesto que Post encuentra en la obra del artista leonés un importante sustrato nativo hispano, sino adquirido durante su formación y relacionado con la obra que Dello Delli está realizando en la sede salmantina ${ }^{41}$. Si bien existe un problema cronológico que no permite afirmar que ésta sea la fuente de esos estilemas desde sus inicios, pues las que se vienen considerando como sus primeras obras, en atención a sus rasgos y características formales, se estiman cronológicamente anteriores a que el florentino y sus hermanos llegaran a España. Se produce por tanto una incoherencia cronológica que Post deja sin resolver, quedando un tanto inconclusa la trayectoria artística que de este pintor se plantea en esta obra ${ }^{42}$.

Las principales contradicciones a la hora de relacionarlo formalmente con el trabajo de Nicolás Florentino se muestran en el abundante uso del oro como fondo, y la concepción espacial del artista leonés,

-

${ }^{39}$ Tanto E. BERTAUX Op. cit. p.771 como A. L. MAYER, La pintura española, Barcelona, 1를. Ed. 1926, $4^{\mathrm{a}}$ Ed. 1949 , p. 81 ven concomitancias evidentes con la obra de Broderlam, lo que contradice CH. R. POST Op. cit, p. 276.

${ }^{40}$ CH. R. POst Op. cit, p. 276 y 281.

${ }^{41}$ La referencia a este artista es constante y los paralelismos estilísticos e iconográficos con su obra reiterados al analizar los murales del claustro para Post son evidentes sobre todo en la escena que representa la Vía Dolorosa o la miniatura de la Natividad de San Isidoro, concretamente refiriéndose al modelo de la Virgen, Idem, p. 269-271.

${ }^{42}$ Idem.. que en ningún momento comparte afinidad con lo italiano ${ }^{43}$.

Sin embargo, a pesar de la permeabilidad a todas las influencias a las que está sometido el artista, la fuerte personalidad de Maestre Nicolás mantiene unos rasgos propios que según Post son principalmente, además de su inusitada creatividad ${ }^{44}$, la fuerte hispanización que manifiesta en algunos aspectos de su obra ${ }^{45}$, y una capacidad de aprendizaje y asimilación que se hará evidente en su evolución como artis$\mathrm{ta}^{46}$.

Los recursos formales utilizados por Maestre Nicolás fueron la base para atribuirle una serie de obras no documentadas

${ }^{43}$ Idem, p. 275-276.

${ }^{44}$ Idem, p. 274 su gran imaginación le permite, dentro de ese ambiente de las artes figurativas del internacional, la creación de multitud de tipos y modelos además de gestos y posturas.

${ }^{45}$ Idem, p. 261, se afirma al principio del capítulo y posteriormente se apoya con ejemplos concretos como la predisposición en el arte hispano a los grupos formales de personajes ricamente ataviados participando de ceremonias como en la tabla del retablo mayor que representa la coronación de San Froilán y que Post considera una de las primeras de este tipo, Idem, p. 277.

${ }^{46}$ Para ilustrar esta idea, el autor se remite en muchas ocasiones a las pinturas del claustro, obra perteneciente al último periodo del artista, cuando con seguridad Nicolás Francés ya había tenido un contacto con la obra de los hermanos Delli en Salamanca y su propio arte habría sido sometido a una paulatina reflexión, a estos murales se refiere el autor para decir: "He almost deserve here the title of a great painter...", comparándolos con los frescos del Quatrocento italiano, Idem, p. 277. Será en la obra del claustro catedralicio donde se muestren evidencias de esa madurez como artista. Las composiciones mostrarán un nuevo poder dramático en su originalidad, el pintor será capaz de introducir todos aquellos subepisodios de género, ahora totalmente integrados en al escena principal, y de manejar su creatividad en una evolución hacia lo caricaturesco plenamente adaptado a estas representaciones. Con gran habilidad dota de un enérgico dinamismo a las escenas mediante multitud de detalles narrativos dentro del mismo episodio, sobre todo en la representación de la Crucifixión y el Descendimiento, Idem, p. 278-279. 
por parte de este autor, que será uno de los más ilustrativos a la hora de esforzarse en describir el estilo del pintor. Chandler R. Post hará un recorrido por aquellas de las que por medio de otros expertos que están trabajando en el tema, como Gómez Moreno o Sánchez Cantón, tiene noticias.

Destaca la consideración que presta a las obras murales, mas desatendidas en otros estudios. Sobre todo se entretiene describiendo las pinturas realizadas en el claustro. El autor profundiza tanto en lo que se refiere a iconografía como al estilo con que se realizaron, mostrando aspectos a los que nadie hasta ahora a vuelto dar la relevancia merecida como es la compleja composición con la que están realizados algunos de los paneles, los recursos narrativos y la evolución estilística de la que se considera su última obra ${ }^{47}$.

Las características formales que se observan en el retablo de la Capilla del Contador Saldaña, en el convento de Santa Clara de Tordesillas, estilísticamente le son tan cercanas a Nicolás Francés, que Post coincide plenamente con Gómez Moreno en atribuirle esta obra sin reservas ${ }^{48}$. La representación del Hortus Conclusus en uno de los paneles, más propio de modelos europeos $^{49}$, sin embargo no le supone ningún reparo para seguir argumentando el italianismo del pintor leonés en la que parece una de sus primeras obras, como tampoco es impedimento que se trate de uno de aquellos retablos mixtos tan abundantes en el ámbito flamenco y borgoñón ${ }^{50}$. Sin em-

\footnotetext{
${ }^{47}$ Idem, p. 277-279.

${ }^{48}$ Idem, p. 284.

${ }^{49}$ Si bien no falta algún ejemplo en el ámbito italiano como el de Stefano da Zevio, conservado en el Museo de Castelvecchio en Verona.

${ }^{50}$ Idem, p. 285, ya nos hemos referido a la refutación por parte de este autor de las teorías que relacionan la producción artística de Nicolás Francés de forma evidente, sobre todo en esta obra, con la de pintores europeos como Broderlam. Cfr nota 39.
}

bargo, el friso que recorre bajo el magnífico alfarje el presbiterio de la capilla mayor, más que al propio maestro lo cree atribuible a un discípulo.

El Museo del Prado aun no había gestionado la adquisición del retablo de procedencia leonesa dedicado a San Francisco y la Virgen cuando el autor estaba realizando su estudio ${ }^{51}$. Chandler R. Post al igual que Sánchez Cantón coinciden al adscribir su ejecución sin duda alguna a Nicolás Francés; en esta obra al igual que en el caso anterior, los rasgos estilísticos delatan la genialidad del pintor leonés, y de nuevo en ella se manifiestan, además de múltiples paralelismos con el retablo mayor de la sede leonesa y con el de Tordesillas ${ }^{52}$, esa influencia italiana a la que constantemente le remite el autor ${ }^{53}$.

El autor celebra el hallazgo en el Museo de Dublín de una de las obras que con más seguridad se consideran de Nicolás Francés y que da a conocer en una adición al Tomo III $^{54}$. Se trata de un San Jerónimo en su estudio que no ha sido en ningún momento discutida posteriormente por ningún estudioso del tema y que se estima de las mejores creaciones del artista.

Menos conocidas son otras obras atribuidas con gran seguridad por parte de este autor a Maestre Nicolás debido los rasgos formales que muestran como la variedad de tipos, los trajes con brocados, la

\footnotetext{
${ }^{51}$ Según el autor por entonces se encontraba en posesión de Don Raimundo Ruiz, Idem, p. 289.

52 Idem, p. 290, las referencias a ambas obras son concretas como manifiesta en el parecido de la habitación donde duerme Inocencio III en uno de los paneles dedicados a San Francisco y los cubículos de los Evangelistas de Tordesillas.

${ }^{53}$ Para el autor existen incluso analogías iconográficas en la Asunción de la Virgen de la escena sobre la tabla central y la representación del mismo tema de Donatello en la tumba de los Brancacci en Nápoles, Idem, p. 289.

${ }^{54}$ Idem, T. VIII, Appendix, p. 681-683.
} 
monumentalidad giottesca y su manifiesto internacionalismo estrechamente conectado con la delicadeza de los miniaturistas. Podemos citar un tríptico con Crucifixión entre santos que el autor considera pudo formar parte de un retablo mayor ${ }^{55}$; también le atribuye un retablo de San Esteban ${ }^{56}$ $\mathrm{y}$, sin tanta convicción, adscribe a Maestre Nicolás una tabla que representa a San Juan Evangelista en la caldera ${ }^{57}$.

Finalmente el autor considera un grupo fragmentario de obras no documentadas y dispersas por humildes iglesias de las provincias de Zamora y Salamanca que se recogen en el catálogo de Gómez Moreno de la provincia de Zamora, incluido en aquella labor de recopilación a principios del siglo $X X^{58}$. Se trata de retazos de obras de mayor envergadura que se han visto expoliadas, su rastro se pierde en colecciones privadas.

En Villalpando, en la iglesia de San Miguel Arcángel, se conservaban cuatro tablas con asunto narrativo alusivas a la leyenda de San Miguel y otras cuatro con representaciones de santos ${ }^{59}$. Cuando Gó-

${ }^{55}$ Perteneciente a la Colección Parcent, Idem, p.
$288-289$.
${ }^{56}$ Por entonces en la colección particular de Gua-
lino en Turín que posteriormente donó gran parte de
sus fondos a la Gallería Sabauda, Idem, T. VII, Appen-
dix, p. 827 .
${ }_{57}$ En posesión de Mr. John W. Higgins en Worcester, Idem, T. VII, Appendix, p. 828.

${ }^{58}$ M. GÓMEZ MORENO, Catálogo monumental de España. Provincia de Zamora. V. I y II. $1^{\mathrm{a}}$ Ed. Madrid, 1927. Ed. Facs. León, 1980. Algunas de ellas vienen recogidas por E. TORMO Y MONZO en Catálogo de las tablas de primitivos españoles de la colección de la Exma. Señora $D^{\underline{a}}$ Trinidad Scholtz-Hermensdorff. Viuda de Iturbe. Madrid, 1911, con ocasión de la exposición en la Real Academia de San Fernando en mayo de 1911.

${ }^{59}$ Las escenas en cuestión tratan los siguientes episodios de la leyenda de San Miguel: la caza del ciervo en el monte Gárgamo, el combate entre ángeles y demonios, la procesión del Papa Gregorio y la construcción del templo de Mont Saint Michel en Francia, y las efigies de los santos corresponden a San Pedro, San mez Moreno las describe no las relaciona con Nicolás Francés, refiriéndose a su autor como el anónimo de Villalpando, pese a que en ellas encuentra ciertos influjos italianos y un inocente realismo ${ }^{60}$. Post ve grandes paralelismos con los murales de León y automáticamente las adscribe a su autoría. En la misma localidad de Villalpando, en la iglesia de Santa María del Templo, sirviendo de altar hubo dos paneles de la Circuncisión y la Muerte de la Virgen descritos en el catálogo y atribuidos al maestro Nicolás que Post ya no logró ver $^{61}$.

En el cercano pueblo de Tapioles Gómez Moreno consideró cercano al mencionado anónimo de Villalpando dos temples acerca de la Circuncisión y la Presentación de Jesús en el Templo que Post considera de un seguidor de Maese Nicolás ${ }^{62}$.

También en relación con el anónimo de Villalpando, Gómez Moreno describió parte de las tablas que componían un retablo en la iglesia de San Félix en Villalobos próximo a los anteriores ${ }^{63}$. El retablo desmantelado del que Post pudo ver tres tablas se considera de un artista cercano al leonés pero menos dotado ${ }^{64}$. Todo esto se vuelve a plantear en posteriores publicaciones de la misma obra, apéndices a los que ya hemos hecho alusión, que para este caso le permiten plantear de forma un tanto vaga la figura del Maestro de Villalobos, deudor de Nicolás Francés en ciertos recursos que ya

Fabián, San Sebastián y San Andrés, CH. R. POST, Op. cit., p. 286.

${ }^{60}$ M. GÓMEZ MORENO, Catálogo monumental de España. Provincia de Zamora, p. 249.

${ }^{61}$ Idem, p. 247 y CH. R. POST, Op. cit., p. 286.

${ }^{62}$ CH. R. POst, Op. cit., p. 286 y M. GÓMEZ MORENO, Catálogo monumental de España. Provincia de Zamora, p. 306.

${ }^{63}$ M. GÓMEZ MORENO, Catálogo monumental de España. Provincia de Zamora, pp. 302-303.

${ }^{64}$ CH. R. POST, Op. cit., p. 287. 
se venía esbozando en capítulos anteriores $^{65}$.

Entre varias obras referenciadas de El Cubo de Don Sancho, localidad en este caso salmantina que sin embargo se incluye en el Catálogo de la provincia de Zamora ${ }^{66}$, procedía un panel de una Crucifixión que Gómez Moreno relaciona con la escuela de Nicolás Florentino mientras a Post le sugiere un tardío seguidor de Nicolás Francés que incluye una clara influencia flamenca tan extendida en esas fechas de la segunda mitad del siglo XV por la geografía castellanoleonesa, en posteriores publicaciones identificado con el mencionado Maestro de Villalobos $^{67}$.

Así pues en la obra de Chandler R. Post se plantea un aspecto muy importante que posteriormente, debido sobre todo a la dispersión de gran parte de una serie de obras, tablas todas pertenecientes a retablos fácilmente expoliables, ha entorpecido el estudio de una posible vía de difusión de la impronta que Nicolás Francés pudo dejar en artistas de su entorno que le sucedieron, rasgos formales o iconográficos que pudieron transmitirse posteriormente incluso en obras que transcendían lo gótico internacional.

Será este autor quien más profundice en esta posible difusión de lo que él califica como escuela leonesa a partir de la obra de Nicolás Francés, y que expone en los sucesivos apéndices de posteriores tomos pertenecientes a la misma obra.

${ }^{65}$ Idem, T. VII, Appendix, p. 829-839, y T. VIII, Appendix, p. 683-685.

${ }^{66}$ M. GÓMEZ MORENO, Catálogo monumental de España. Provincia de Zamora, p. 307. Según Gómez Moreno, la obra pasó a la colección Trauman y Post la localizó en la perteneciente a John Nicholas Brown, C. R. POST, Op. cit., p. 291-292.

${ }^{67}$ Idem, T. VII, Appendix, p. 833.
Advierte gran influencia en una serie de representaciones de santos y profetas de medio cuerpo, propio de las predelas que frecuentemente realizó el artista del tipo de la del retablo del Museo del Prado; detalla dos fragmentos de una predela en la iglesia parroquial de Mansilla de las Mulas, población cercana a León, y otra semejante en la iglesia de Astudillo al noreste de Palencia. Otras obras en las que el autor también advierte influencia de Nicolás Francés son: una tabla con la representación del Éxtasis de María Magdalena entre la capilla mayor y el ábside en la catedral de Palencia, que no se conserva, parte de las tablas del retablo de la iglesia parroquial de Villamediana o algunas del de San Miguel de Vertavillo también en la provincia de Palencia. Algunas delatan ya una tendencia hacia las formas flamencas que se iban extendiendo por toda Castilla pero aun mantienen rasgos que muestran la impronta del pintor leonés como en la aldea de Terradillos de Esgue$\mathrm{va}^{68}$, sin olvidar la única obra a la que en otros autores siempre se hace referencia: la Anunciación del Museo Fogg en Harvard firmado por Juan de Burgos, según Post, tal vez el mismo Juan que se menciona al cuidado de las vidrieras de León en $1452^{69}$.

Este asunto queda planteado de forma un tanto desdibujada e inconcreta por parte del autor, y fuera del alcance de nuestro objetivo el tratar de darle forma o profundizar de alguna manera que transcendiera de lo que constituye un estado de la cuestión. Sin embargo consideramos que se trata de un asunto que reclama un estudio serio para esclarecer las posibles reminiscencias de la labor del artista.

Será Francisco José Sánchez Cantón quien realice la primera publicación de tipo monográfico acerca del pintor, surgida a

${ }^{68}$ Idem, T. IV, Appendix, (1933), pp. 656-660.

${ }^{69}$ Idem, p. 292-296. 
raíz de la presentación de una ponencia en el Congreso de Historia del Arte celebrado en París en otoño de 1921, impreso en actas en $1924^{70}$, que el mismo autor amplió para publicar en el número 1 de la revista Archivo Español de Arte y Arqueología ${ }^{71}$, y que concluiría en 1964 con la única obra dedicada a este artista en su totalidad, que al igual que la referencia anterior lleva por título Maestre Nicolás Francés, perteneciente a la serie "Artes y Artistas", editado por el Instituto Diego Velázquez del Consejo Superior de Investigaciones Científicas ${ }^{72}$.

En todos los casos el autor se explaya en lo que considera excepcional para un artista de la época: la riqueza en cuanto a noticias documentales. La principal preocupación que muestra Sánchez Cantón es la de demostrar el origen del artista, que si en sus primeros escritos se inclina por una formación italiana ${ }^{73}$, posteriormente se esforzará intentando demostrar que su procedencia es definitivamente francesa, más exactamente borgoñona ${ }^{74}$. Para ello primeramente se basa en la información sobre el maestro que aparece en el relato de Pero Rodríguez de Lena de la Crónica del Passo Honroso de Don Suero de Quiñones ${ }^{75}$; el breve apunte que de la crónica hizo Gómez Moreno ${ }^{76}$ le sirvió para valorar la referencia

\section{-}

${ }^{70}$ F. J. SANCHEZ CANTON, “Maître Nicolás Francés, peintre du la premier moitié du XV", Actes du Congrés d'Histoire de l'art, París, 1924, T. II, pp. 239-259.

71 F. J. SÁNCHEZ CANTÓN, "Maestre Nicolás Francés", Archivo Español de Arte y Arqueología, n. 1, 1925, pp. 41-65.

${ }^{72}$ F. J. SÁNCHEZ CANTÓN, Maestre Nicolás Francés, Madrid, 1964.

${ }^{73}$ En 1928 escribiría refiriéndose a la implicación del artista en las vidrieras de la catedral leonesa: "Este es un nuevo dato para robustecer la idea de la formación italiana de Maestre Nicolás..." en F. J. SÁNCHEZ CANTÓN, "Maestre...", p. 53.

${ }^{74}$ F. J. SÁNCHEZ CANTÓN, Maestre Nicolás ..., p. 14.

${ }^{75}$ F. J. SÁNCHEZ CANTÓN, “Maestre...", p. 42 y Maestre Nicolás..., p. 10.

${ }^{76}$ La referencia del artista en el texto M. GÓMEZ MORENO, “jJoosken de Utrecht...", p. 65. Cfr.: nota 14. que se hace del pintor como "el sotil maestro Nicolao Francés" 77 , queriendo indicar a partir de ello, además de la autoría tanto del retablo de la catedral leonesa como de la figura que sirviera de faraute para la empresa caballeresca, la procedencia del artista.

Otra referencia documental merecedora de especial detenimiento según Sánchez Cantón es el documento de 1435 perteneciente al Libro de rentas de la Catedral de León, en relación al alquiler de la casa en la que habitaba el pintor en la calle Cardiles, en el que se menciona la labor "de debojar las vidrieras" para la que se ofrece el artista en la catedral, y sobre la que otro documento de 1445 añade que "es bien necesario". Pero son muchas las citas procedentes del archivo de la catedral de las que el autor da noticia que muestran la relación permanente entre el pintor y el cabildo $^{78}$, y que Sánchez Cantón interpreta como prueba del cargo de Maestro mayor ${ }^{79}$.

La parte decisiva del estudio de Sánchez Cantón lo constituye el análisis que se hace de las obras atribuidas a Maestre Nicolás.

La obra a la que este autor dedica una mayor atención es el ya citado retablo mayor de la iglesia de Santa María de Re-

${ }^{77}$ Así se le menciona en la Crónica aunque luego en los demás documentos será siempre Nicolás, observación hecha en F. J. SÁNCHEZ CANTÓN, "Maestre...", p. 42.

${ }^{78}$ Cita por años los documentos donde se menciona: el encargo de un pendón de lienzo, limpiar el trono del retablo, dorar la corona del rey, dorar el león, la descripción de una visita a su casa, la causa a determinar por el juez de su segunda esposa. Y sin referir fecha enumera otras labores como: dibujar vidrieras, pintar la tabla del altar menor, el Juicio Final, las pinturas murales por encima del retablo, la capilla de la Virgen del Dado y el claustro. F. J. SÁNCHEZ CANTÓN, Maestre Nicolás..., pp. 12-14.

${ }^{79}$ Lo que apoya en que, como consta documentalmente, le correspondía un sueldo fijo anual de 5000 maravedís, Idem, p. 13. 
gla, al que se hace alusión en la Crónica de Pero Rodríguez de Lena. Su descripción es posible gracias a un documento del siglo XVIII perteneciente el archivo catedralicio que lo detalla, si bien a su juicio, en él se exagera sobre el número de tablas que lo compondrían en su origen ${ }^{80}$. Tras los avatares que sufrió entre su desmonte en el siglo XVIII hasta su parcial reposición a principios de los años $X X$, tabla a tabla se van describiendo a la vez que se aportan las posibles fuentes iconográficas. Sirviéndose de la descripción del documento número 1801 y los detalles que se aportan del retablo, Sánchez Cantón valora incluso los paneles perdidos ${ }^{81}$, conjeturando acerca de la presencia de rasgos flamencos semejantes al Maestro Flémalle en la escena de la Anunciación $^{82}$.

Coincide plenamente con Gómez Moreno en la atribución de la miniatura de la biblioteca isidoriana al maestro Nicolás. Sin embargo matiza la participación del artista en el retablo de la Capilla del Contador Saldaña en Tordesillas que Gómez Moreno y Chandler R. Post le adjudicaron sin reservas. Sánchez Cantón aprecia cierta irregularidad en la realización de los paneles, ve rasgos más arcaicos en el cuerpo bajo del interior, y sin embargo una mejor ejecución en las imágenes de los Evangelistas, lo que le lleva a pensar en al participación de otro colaborador menos capaz, o que es una obra primeriza en la que el autor aún no estaba totalmente formado. También menciona el friso que se extiende bajo el

-

${ }^{80}$ Archivo de la Catedral de León, Doc. 1801, Se reproduce íntegro en F. J. SÁNCHEZ CANTÓN, “Maestre..." Apéndice B, pp. 60-64.

${ }^{81}$ En F. J. SÁNCHEZ CANTÓN, “Maestre...", 1928, sólo les cita.

${ }^{82}$ F. J. SÁNCHEZ CANTÓN, Maestre Nicolás..., p. 12. Ya había encontrado relación con el Maestro Flémalle en sus primeros artículos respecto al origen de las anécdotas burlescas que el artista incluía en las escenas principales F. J. SÁNCHEZ CANTÓN, "Maestre Nicolás..., p. 48. espléndido alfarje morisco de la capilla mayor de la iglesia, coincidiendo con Chandler R. Post, al considerarlo relacionado con el círculo del maestro pero no de ejecución propia, refiriéndose a la pintura de las cuarenta y tres figuras de santos de medio cuerpo que lo recorre. La participación de Maestre Nicolás en la obra decorativa de Tordesillas, que como relatamos le pone en conexión con el maestro de obra Guillén de Rouen, de ascendencia nórdica, sirve al autor para reafirmar su teoría acerca del origen francés del artista.

Aunque no la incluye hasta la publicación de $1964^{83}$, Sánchez Cantón juzga el retablo de San Francisco que se expone en el Museo del Prado como obra notable del maestro leonés. Hace una breve alusión a la técnica que considera como ejecución al óleo, sin aducir ningún argumento más que la intensidad del color que lucen las tablas, y que más adecuadamente debería describirse como temple con veladuras al óleo sobre tabla ${ }^{84}$.

La importancia que se adjudica a esta obra le obliga a un escrupuloso análisis desde la descripción de sus escenas a los rasgos formales, en los que el autor intuye de nuevo esa ascendencia europea del artista, más concretamente de Flandes y Borgoña, para él evidente en la escena de la Purificación, perteneciente a la calle lateral de-

\footnotetext{
${ }^{83}$ Esta obra no aparece citada por este autor en sus primeras publicaciones, ni cuando en la parte correspondiente al Apéndice $C$ de su obra F. J. SÁNCHEZ CANTÓN, "Maestre Nicolás...", pp. 64-65, hace un repaso por obras a las que sin ser atribuidas a Nicolás Francés las considera cercanas a su estilo.

${ }^{84}$ Idem, p. 22. Sin embargo en F. J. SÁNCHEZ CANTÓN, "Maestre Nicolás...", p. 45 y 57 el autor se entretiene en describir de forma más precisa la técnica utilizada en alguna de las obras como temple de huevo sobre tablas de álamo blanco con lienzo pegado y aparejadas con yeso.
} 
recha dedicada al igual que la central a la Virgen $^{85}$.

En la calle lateral izquierda, en el bloque dedicado a San Francisco, destaca la originalidad iconográfica. Entre las tres escenas dedicadas a la vida del santo, inspiradas en la narración de I fioretti, destaca la que representa su estigmatización. Sánchez Cantón la interpreta como un único episodio al identificar al personaje que se postra en tierra como Fra Leone con otros compañeros absortos ante el prodigio, y no como la representación del milagro de la fuente, en el que el santo sacia la sed del hombre que le había socorrido cuando estaba enfermo, uniendo varios sucesos en una misma escena como un recurso narrativo que no parece ser bien entendido por este autor.

Un aspecto de Nicolás Francés que Sánchez Cantón no pasa por alto es ese gusto por lo anecdótico, que en ocasiones interpreta como humorístico, y que se plasma en esos episodios secundarios que frecuentemente incluye con gran ingenio en las escenas principales.

También atiende otras obras aportadas por Chandler R. Post, que de modo más disperso se adscriben a la autoría de $\mathrm{Ni}$ colás Francés y con la que en ocasiones disiente.

No sucede lo mismo con el retablo de San Jerónimo en su estudio de la National Gallery de Dublín, ni tampoco con el que pudo ser un retablo dedicado a San Miguel Arcángel del que describe tres de las tablas ${ }^{86}$, una de las cuales se expuso en la

\footnotetext{
${ }^{85}$ Encuentra una evidente similitud con idénticas figurillas que se ven en pinturas y miniaturas nórdicas que el artista también añade a los edificios con que ambienta las escenas a imitación de aquella escultura monumental que tan gran desarrollo tuvo en la arquitectura europea. F. J. SÁNCHEZ CANTÓN, Maestre Nicolás..., p. 23.

${ }^{86}$ Las tablas salieron de la colección privada de D. Javier Bosquet, de Barcelona. Idem, p. 26.
}

muestra de arte español celebrada el año 1959 en el Museo Nacional de Estocolmo, provocando la adquisición de la obra por este Museo ${ }^{87}$. Ambas se consideran de suficiente calidad como para adjudicárselas sin reservas.

Tampoco se pone en duda la atribución de la tabla "El martirio de San Juan Evangelista en la caldera" ${ }^{\prime 88}$.

Pese a reconocer la gran aportación de Chandler R. Post, como hemos advertido anteriormente no siempre está plenamente de acuerdo con las atribuciones que el estudioso norteamericano hace al artista leonés. Algunas obras le infunden no pocas dudas a la hora de asignárselas plenamente al Maestre Nicolás. Así sucede con La Misa de San Gregorio del Museo de Boston, La Crucifixión entre San Pedro y San Andrés de la Duquesa Parcent, la Crucifixión de la Colección Brown o El bautismo de San Marcial de la Colección Gualino de Milán.

El interés por probar la procedencia de los aspectos formales a los que recurre el artista será el asunto en que ambos estudiosos muestren posturas diametralmente opuestas. Para Post como ya expusimos, su inspiración formal procede principalmente del mundo italiano, mientras Sánchez Cantón destaca las evidentes recurrencias de procedencia nórdica, que justificarían ese origen francés que le atribuye y que encaja con su apellido ${ }^{89}$.

\section{-}

${ }^{87}$ J. GUDIOL RICART, "Spanish painting in Stockholm", Burlington Magazine, n. 102, 1960, pp. 225-226.

${ }^{88}$ Sánchez Cantón la localiza en la Colección Higgins, F. J. SÁNCHEZ CANTÓN, Maestre Nicolás..., p. 26.

${ }^{89}$ El desacuerdo de Sánchez Cantón con los autores que opinan una mayor influencia italiana en la obra de Nicolás Francés se pone de evidencia cuando no le reconoce un uso de los característicos recursos italianos de espacio y perspectiva, ni aún después de haber visto la obra de los hermanos Delli en la Catedral de Salamanca, Idem, p. 25. 
Por último, si cuando Sánchez Cantón describe las obras en tabla hace alusión un tanto simplista de la técnica del óleo, e incluso considera a Nicolás Francés un virtuoso en su manejo, la descripción de la técnica de los murales es más acertada al ser descritas como obras al temple ${ }^{90}$, pero poco se entretiene en estas obras el autor de este estudio, mencionando someramente el documentado pero perdido Juicio Final, cuya ubicación confunde al localizarlo en la bóveda sobre el retablo mayor ${ }^{91}$, y la gran serie de murales del claustro, de la que lamenta su estado y advierte aportaciones de otros artistas en alguna de las composiciones. Sin profundizar, también le atribuye la pintura de la girola que muestra la escena de "Jesús ante el pueblo" a la que considera de su último periodo y finaliza aludiendo brevemente a los murales de la Capilla de San Fabián y San Sebastián hoy de Santa Teresa ${ }^{92}$.

Queda la investigación de este autor un poco escasa de argumentos razonados en lo que son los aspectos formales a la hora de afirmar o disentir la atribución de algunas obras, y en la rotundidad con la que el autor defiende el origen nórdico del pintor, habiéndose inclinado en un primer momento por la prevalencia de la influencia italiana en la obra del artista. Se echa en falta una justificación basada en un análisis comparativo con obras y autores de origen europeo con los que establecer unas relaciones que ilustren las afirmaciones mante-

${ }^{90}$ Por ello le niega la consideración de fresquista, Idem, p. 28, pues verdaderamente esta técnica no se ejecutaba sobre el soporte fresco. El enlucido que se aplicaba para pintar al temple no necesitaba de estar húmedo, se pintaba sobre un estuco seco.

${ }^{91}$ La equivocación tuvo que ser motivada al relacionarlo con la obra del mismo tema que se estaba llevando a cabo por Nicolás Florentino en Salamanca y la visita que se le comisionó al artista para verla. Idem.

${ }^{92}$ Idem, p. 28- 29. nidas por el autor y la rectificación de su opinión inicial.

Como hemos expuesto, la dispersión sufrida por la obra de Nicolás Francés y sus seguidores por el despojo de gran parte de sus encargos, desperdigó gran parte de las pinturas por las manos de una serie de coleccionistas privados, muchas de las veces con paraderos muy complicados de esclarecer. En 1987 un artículo de Matías Díaz Padrón en la revista Goya hizo pública la atribución al maestro de una tabla catalogada para la venta por la galería Christie's junto con otras dos tablas de artistas castellanos del siglo $\mathrm{XV}^{93}$.

Se trata de la representación de una pareja de santos que por sus atributos son identificados por el autor del artículo con San Antonio Abad junto al león y San Lorenzo con la parrilla. Las razones para la atribución a Maese Nicolás, de quien aquí se admite su procedencia francesa, se basan en un somero análisis formal, un estudio comparativo de rasgos comunes con los que presentan otras obras que se le reconocen seguras al artista, principalmente rostros, nimbos, siluetas y pavimento, similares a los que presenta el retablo de la catedral de León, a cuyos despojos, se insinúa podría pertenecer esta tabla.

\footnotetext{
${ }^{93}$ M. DÍAZ PADRÓN, "Tras tablas restituidas a importantes maestros de Tierra de Campos. Nicolás Francés, Fernando Gallego y Juan Sureda", Goya, n. 197, 1987, pp. 270-273. El autor no explica la referencia geográfica tan concreta que implica la comarca de Tierra de Campos. Estas y otras tablas habían sido presentadas en subasta, para lo que la galería Christie's de Londres publicó el catálogo: Catalogue of the final partion of important pictures by old master chiefly of the dutch, flemish, french, spanish and british school the property od the late Sir George Lindsay Holford. Sale May 17-18, 1966. La obra en cuestión se incluía con el número 51.
} 


\section{ÚLTIMAS PRECISIONES}

Tras la tarea investigadora de Francisco Javier Sánchez Cantón, el estudio acerca de la personalidad artística de Maese Nicolás Francés se ralentizó bruscamente. Salvo el artículo de Matías Díaz Padrón, alguna breve referencia en obras generales y catálogos ${ }^{94}$, alguna cita remitiéndose a la labor ya hecha o alguna alusión en relación con algún aspecto concreto ${ }^{95}$, no se abundó

\footnotetext{
94 Por supuesto no faltaron los reconocimientos y referencias a este artista en obras generales como J. GUDIOL RICART, "La pintura gótica", Ars Hispaniae, T.IX, Madrid, 1955, pp. 229-233, en donde ya se admite el origen nórdico del pintor, más concretamente su relación con el ámbito artístico parisino en torno a 1400 , además de proponerle de forma un tanto arriesgada como el origen para el florecimiento de una escuela hispanoflamenca a finales del siglo XV. Por otra parte en J. CAMÓN AZNAR, "Pintura medieval española", Summa Artis, T. XXII, Madrid, 1966, pp. 347-354, se hace una valoración menos comprometida aunque con abundantes datos biográficos, se describen los principales aspectos estilísticos de las obras, se hace referencia a las fuentes iconográficas que utiliza el artista y en numerosas ocasiones se remite a los expertos que por entonces habían hecho las principales aportaciones. Tampoco faltan las alusiones al artista en las monografías que tratan del museo del Prado como la obra de E. LAFUENTE FERRARI, El Prado. Del Románico al Greco, Madrid, 1967, pp. 69-75, que se remite a aspectos ya conocidos sin aportar nada nuevo, centrándose como es natural en el "Retablo de San Francisco" o los catálogos como Catálogo de las pinturas, Madrid, 1985 , p. 465, en el que tan solo se describen las escenas del mencionado retablo sin aludir siquiera a la técnica.

${ }^{95}$ Algunas noticias se dieron a conocer por periódicos locales incluidas en su suplemento cultural, es el caso del artículo de A. VALDERAS, "El retablo de Hinojo", Diario de León, Filandón, 25 de febrero de 1990, pp. 14-15, que se centra en la procedencia del retablo de San Francisco del Prado y propone la hipótesis de que su lugar original fuera la capilla de Santa María del Convento de San Francisco de Astorga, panteón de la familia Bazán hasta 1460; en la misma publicación se difundió el descubrimiento y restauración de una tabla atribuida a Nicolás Francés perteneciente a los despojos del retablo mayor tras su desmonte que se encontró reutilizada como soporte de un asiento en la parroquia de Trobajo del Camino, M. Gómez RAsCón, “Un Nicolás Francés debajo de un sillón", Diario de León, Filandón, 30 de Octubre de 1994, pp. IV-V.
}

en la materia hasta la reanudación del estudio por Joaquín Yarza Luaces.

En tres ocasiones este autor ha tenido ocasión de tratar el tema aportando, después de varias décadas, juicios y valoraciones. Las circunstancias en que se ha procedido a estos estudios vienen marcadas por acontecimientos con los que la obra del artista se ha visto revalorizada.

Con ocasión de la restauración de las pinturas murales del claustro de la Catedral de León, cuya intervención fue llevada a cabo entre los años 1994 y 1995, se procedió a una serie de estudios técnicos, formales e iconográficos, que se reflejaron en una publicación de $1997^{96}$. En ella Joaquín Yarza hace un repaso por las principales obras del artista leonés, de las que se sirve para hacer un análisis estilístico que le permita un juicio concluyente en lo que a la procedencia, origen y formación del artista se refie$\mathrm{re}^{97}$. La contribución más significativa que aquí hace el autor es la ratificación de la tesis de Sánchez Cantón con respecto al origen y formación del artista. Pero Joaquín Yarza se muestra más preciso en su consideración al aportar pruebas inconfundibles de que el artista conocía los recursos formales que se practicaban en Francia y los Países Bajos, concretamente de la zona entre París y Tournai ${ }^{98}$. Las circunstancias de su llegada a España, sin pruebas que lo atestigüen, se pueden poner en relación con la diáspora de artistas procedente de las grandes cortes francesas tras la desaparición de algunos de los principales clientes y la ocupación de París por los ingleses ${ }^{99}$. Las condiciones en que se asentó en León están aun por determinar.

-

${ }^{96}$ Vv.AA. Restauración de las pinturas murales del claustro de la Catedral de León, Valladolid, 1997.

97 J. YARZA LUACES, “Un perfil de Nicolás Francés", en Idem, pp. 11-23.

$$
\begin{aligned}
& { }^{98} \text { Idem. } \\
& { }_{99} \text { Idem, p. 11-12. }
\end{aligned}
$$


En el análisis de los aspectos formales se buscan las fuentes precisas y se dan las pistas de sus recursos en obras y autores concretos que el autor encuentra en miniaturistas anónimos como el del manuscrito Terencio de los Duques, el Maestro de Horas Bedford y el Maestro Jean Malouel ${ }^{100}$. Cuando en el año 2004 se publican las Actas del Congreso Internacional: La Catedral de León en la Edad Media ${ }^{101}$, celebrado en abril del año anterior, el autor vuelve sobre el tema para en esta ocasión relacionar la obra del pintor leonés sobre todo con el Maestro Boucicaut ${ }^{102}$.

Con todo se aparta de la idea que manifestaba Chandler R. Post acerca del italianismo sobre un poderoso sustrato hispano que mostraban las obras de Nicolás Francés y que tan evidente le era al autor norteamericano. La hispanización que se observa, según Joaquín Yarza, habría que achacarla únicamente al imperativo del cliente $^{103}$.

En su análisis de las obras, el autor se detiene en el aspecto iconográfico de escenas como el Hortus Conclusus del retablo del Contador Saldaña en las Claras de Tordesillas ${ }^{104}$, la tabla de la estigmatización de San Francisco en el retablo del Museo del Prado ${ }^{105}$, el mural del Ecce Homo de la

100 Idem, p. 12-13.

101 J. YARZA LUACES, "Artes del color en el siglo XV en la Catedral de León", Actas del Congreso Internacional: La Catedral de León en la Edad Media", del 7 al 11 de abril de 2003, León, 2004, pp. 399-431.

${ }^{102}$ Idem, p.416-417.

103 J. YARZA LUACES, “Un perfil...”, p. 13.

${ }^{104}$ Idem, p. 13-14, también CH. R. POST, Op. cit., V. III, 1930, p. 283, en su análisis de la labor pictórica de este retablo ha reparado en esta escena, en su simbología y en lo poco frecuente en el ámbito castellanoleonés, del que reconoce ejemplos en Verona, Cataluña y Valencia, pero sobre todo perteneciente al ámbito artístico nórdico.

105 J. YARZA LUACES, "Un perfil...", p. 19, esta escena se interpreta de forma distinta a como lo hiciera Sánchez Cantón, donde éste ve a los tres frailes com- girola de la catedral leonesa, según el autor la primera representación de este tema en el arte español ${ }^{106}$, pero sobre todo en lo que se conserva del retablo mayor del templo catedralicio ${ }^{107}$.

Otro aspecto iconográfico que destaca en la obra de Nicolás Francés es la representación del "doble credo" que nos revela un bancal adquirido por el Museo Santa Cruz de Toledo, cuya restauración ocasionó

pañeros del santo participando absortos del extraordinario suceso y cree a Fra Leone postrado en tierra, Joaquín Yarza ve una conjunción de distintos episodios representados a la vez en un mismo registro, en uno de ellos se representa el prodigio en el que se hace brotar agua del suelo para saciar la sed del hombre que socorrió al santo cuando estaba enfermo, y que sería el personaje que arroja sobre una especie de riachuelo, a parte de la escena central que representa propiamente la estigmatización. Apoya esta teoría el que es un recurso narrativo frecuente en Nicolás Francés. Esta concatenación de episodios en una misma escena podemos también observarla en la tabla que representa la Traslación del cuerpo de Santiago por sus discípulos perteneciente al retablo mayor de la catedral.

${ }^{106}$ J. YARZA LUACES, "Artes del color..."pp. 417420. El autor cita alguno de los antecedentes de este episodio en el arte europeo y describe la escena en la que destaca la importancia de los textos inscritos en cartelas y al igual que CH. R. POST, Op. cit., V. III, 1930, p. 281, advierte del uso de estas fórmulas en la liturgia de la Semana Santa, concretamente al llamar la atención sobre la figura femenina arrodillada en el extremo inferior izquierdo que parece ser el donante.

${ }^{107}$ Será la descripción de aquellas escenas del retablo mayor de la catedral de León que se conservan en las que más se detenga el autor, recreando detalles e iconografía también de las numerosas tablas con representaciones de santos que formaron parte de la silla episcopal y que hoy se conservan en el museo diocesano. Vuelve a encontrarse coincidencias con F. J. SÁNCHEZ CANTÓN, “Maestre Nicolás...", (1925), p. 69 y Maestre Nicolás..., (1964), p. 16. al referirse al Tríptico de Merode comparándole con la tabla que representa la Anunciación, y la de la Presentación, haciendo referencia al número de escaleras que le suben hacia el altar con carácter simbólico en relación a los salmos, si bien al respecto CH. R. POST, Op. cit., V. III, 1930, p. 276, corrige el número de peldaños y contradice ese paralelismo con el arte francés. 
la tercera publicación de Joaquín Yarza respecto a la obra del artista $^{108}$.

Joaquín Yarza reconoce dos importantes méritos al artista que son por un lado, la intencionalidad de esos episodios de género secundarios, siempre representados a menor escala, a los que nos hemos referido en numerosas ocasiones, y que el autor interpreta más allá de lo meramente anecdótico como glosas marginales añadidas al tema principal ${ }^{109}$ y por otro, la representación de efigies que del carácter fisonómico medieval pasan a acercarse a una individualización de los rostros que el arte moderno desarrollará hasta el triunfo del retrato como género ${ }^{110}$.

El punto más conflictivo de todo el estudio se centra en lo relativo a establecer periodos cronológicos en cuanto al desarrollo de su personalidad artística y la datación de algunas obras. Es admitido que el artista estaba trabajando en León en $1434^{111}$; el que hubiera concluido el encargo del retablo principal, tal y como viene relatado en la Crónica del Passo Honroso de Rodríguez de Lena podría verse corregido si aceptamos la posibilidad que este dato se hubiera añadido tiempo después, o incluso el ma-

108 J. YARZA LUACES, “Nicolás Francés, bancal del Credo de los apóstoles", El Apostolado de Nicolás Francés, Toledo, 1999, pp. 11-35.

${ }^{109}$ El ejemplo que utiliza el autor para ilustrar esta intencionalidad se encuentra en la escena de la Visita de Alfonso III a San Froilán en el retablo de la catedral, la pareja que se muestran impúdicamente simbolizando las "procacioribus verbis" con que el santo quería mostrar su indignidad a ocupar la sede leonesa, J. YARZA LUACES, “Artes del color...", pp. 408.

${ }^{110}$ Idem, pp. 409 lo que vuelve a remitir a miniaturistas parisinos de la talla del Maestro de las Horas Boucicaut.

${ }^{111}$ La realización del "faraute" para exhibición del Passo de don Suero tuvo que realizarse en fecha cercana a la celebración en verano de 1434, Idem, p. 402. nuscrito no se hubiera realizado en el tiempo real del acontecimiento ${ }^{112}$.

A Joaquín Yarza esto le supone un punto de fricción al intentar establecer una cronología correlativa entre las obras que indique la evolución del pintor, es decir, estilísticamente parece anterior el retablo del Contador Saldaña, lo que implicaría que Nicolás Francés ya se encontraba en España antes de 1434. Pero la Capilla a la que se destinó esta obra se concluye en 1435 y la imagen del personaje que se supone como el donante, don Fernando López de Saldaña, en la misma escena que uno de los evangelistas, sin ninguna de sus mujeres, pese a que los escudos de ambas aparecen en la capilla, lleva a pensar al autor que debió de realizarse en el tiempo en que, viudo desde 1433 de su primera esposa, aún no había contraído matrimonio con la segunda ${ }^{113}$, sin finalmente poder resolver el dilema de las circunstancias que permitan en tiempo tan cercano ejecutar obras tan distintas como son el retablo del Contador en Tordesillas y el del altar mayor de la catedral de León.

Una aportación que abunda a este respecto proviene de los estudios realizados por Clementina Ara Gil en su trabajo acerca de la escultura gótica en la provincia de Valladolid quien plantea un análisis de la obra de Tordesillas desde su elemento escultórico $^{114}$, estudios ya iniciados a princi-

${ }^{112}$ Esta es una teoría que ya consideraba $\mathrm{CH}$. R. POST, Op. cit., V. III, 1930, p. 262, donde el historiador norteamericano reconoce la posibilidad de que, aunque los detalles que muestra la Crónica indican que fue escrita en el tiempo del suceso, Rodríguez de Lena más tarde insertara la referencia al retablo.

113 J. YARZA LUACES, “Artes del color..."p. 404.

${ }^{114}$ Sus teorías se exponen principalmente en C. J. ARA GIL, Escultura gótica en Valladolid y su provincia, Valladolid, 1977, y C. J. ARA GIL Y J. M. PARRADO DEL OLMO, "Real convento de Santa Clara de Tordesillas" en Catálogo monumental. Antiguo partido judicial de Tordesillas, Valladolid, 1980, pp.284-295, de donde se extraen para VV. AA., La España gótica. Castilla y León, 
pios del siglo XX por Bertaux, Weise o Gómez Moreno a los que ya nos hemos referido. Tanto lo que aporta la documentación, como la inscripción del entablamento de dicha capilla que data a la obra en $1435^{115}$, como la lápida del aparejador Guillem de Rohan, muerto en $1431^{116}$, confirmarían la cronología que posteriormente Joaquín Yarza propone para el retablo.

En la obra de Ara Gil se vuelve a considerar la posibilidad de que Nicolás Francés hubiese colaborado en la talla del retablo ${ }^{117}$. La autora baraja dos argumentos que reconoce no son en manera alguna definitivos. Uno es la representación de un mismo tipo de vallado que se repite en la talla y en la pintura ${ }^{118}$, y que se reconoce

V. I, Madrid, 1989, p. 335. La cuestión de las distintas soluciones al respecto de la intervención de Nicolás Francés como escultor y las posibles conexiones con Guillem de Rohan y el Maestre Jusquín se recogen en D. TeIjeIra PABlos, "La última escultura gótica. Las obras del siglo XV" en Actas del Congreso Internacional: La Catedral de León en la Edad Media. León 7-11 de abril de 2003, León, 2004, pp. 381-397. Acerca de la arquitectura $\mathrm{y}$ los maestros que participaron en esta empresa $\mathrm{J}$. CASTÁN LANASPA, Arquitectura gótica religiosa en Valladolid y su provincia, (siglos XIII-XVI), Valladolid, 1998, pp. 554-569, donde se aportan datos que refuerzan la relación entre los artífices de la Capilla del Contador y los que trabajaban en la Seo leonesa, como concretamente demuestra el contrato en 1441 de la realización de las vidrieras para la tracería flamígera de la capilla a cargo del maestro vidriero Valdovín de León, quien para la ejecución del trabajo se trasladó a Tordesillas donde permaneció durante todo el mes de agosto del mismo año.

${ }^{115}$ C. J. ARA Gil Y J. M. PARRado Del Olmo, “Real convento de Santa Clara..., p. 286.

${ }^{116}$ Cfr. nota 16.

${ }^{117}$ Se remonta a argumentos como los de Sánchez Cantón cuando considera que a cargo de un gran taller oficiales destinados a diferentes labores trabajarían a su cargo, además de utilizar las referencias acerca de la realización del faraute, no solo de la pintura, C. J. ARA GIL, Escultura gótica..., p. 207.

${ }^{118}$ Por ejemplo en la escena de la Virgen y el Niño en el "Hortus conclusus" de las puertas exteriores o en la del "Noli me tangere" de la parte interior. como no exclusivo ${ }^{119}$. El otro motivo que pudiera llevar a considerar la participación de Nicolás Francés en la escultura de esta obra sería de mayor consistencia, tendría que ver con la escultura de la Virgen que presidía el retablo original que el maestro realizó para la catedral de León, que junto con el retablo de Gavilán Tomé pasó a la iglesia de los capuchinos en León. Se trata de una talla que siendo de calidad superior a la del retablo de Tordesillas mantiene rasgos comunes sin que pueda descartarse sean del mismo autor, y desde luego en último término afecte a las circunstancias laborales de Nicolás Francés.

Dadas las peculiaridades de la pintura de este artista, también hay autores que se han centrado prioritariamente en lo que a su iconografía se refiere. Las escenas representadas en los muros del claustro de la catedral leonesa han ocasionado el interés de algunos autores, es el caso de Máximo Gómez Rascón ${ }^{120}$ o de Ángela Franco Ma$\mathrm{ta}^{121}$. En el primer caso se trata de una descripción de cada uno de los episodios allí representados, cabe destacar la observación de Joaquín Yarza con relación a la escena

-

${ }^{119}$ Podemos observar el mismo motivo en la escena de la Oración en el huerto de los Olivos en el retablo de Dello Delli para la catedral vieja de Salamanca, aunque en el resto de las escenas utiliza otros tipos de vallas y empalizadas.

120 M. GÓMEZ RASCÓN, "Pinturas de Nicolás Francés en el claustro de la catedral de León. Aproximación iconológica" en Restauración de las pinturas del claustro de la catedral de León, Valladolid, 1997, pp. 2755, coincide en la identificación de la mayoría de las escenas con la que hizo en su día CH. R. POST, Op. cit., T. III, p. 265-266, excepto las que para Gómez Rascón son Los familiares de Jesús, en La predicación de San Juan y el Bautismo de Cristo, Las tentaciones de Jesús, La oración del huerto, cuatro escenas entre una treintena de murales cuyo estado de conservación hace imposible el reconocimiento de algunas.

${ }^{121}$ A. FRANCO MATA, "El claustro de la catedral de León. Su significado en el contexto litúrgico y devocional", en Actas del Congreso Internacional: La Catedral de León en la Edad Media. León 7-11 de abril de 2003, León, 2004, sobre todo pp. 288-295. 
que trata el lavatorio de Pilatos ${ }^{122}$ y que en Máximo Gómez Rascón no se interpreta como un Ecce Homo, tal como hace Chandler R. Post ${ }^{123}$, sino como la "Condena a muerte de Jesús" ${ }^{124}$.

Por otro lado Ángela Franco Mata observa una imagen superpuesta en la escena del Santo Entierro, se refiere a ello con el término palimpsesto por considerar esa parte posterior a otra pintura subyacente. Lo relaciona con el contexto de la muerte y las danzas macabras frecuentes en la Europa bajomedieval, y de las que aunque no de forma tan extendida, también existen ejemplos en el ámbito peninsular ${ }^{125}$.

De la misma autora son también las interpretaciones en relación a la predela del Museo de Santa Cruz de Toledo o a la colección de santos pertenecientes al retablo original de la catedral de León que aluden al Doble Credo de Apóstoles y Profetas analógicamente expuesto mediante textos en cartelas y rótulos ${ }^{126}$; también hace referencia a esta iconografía Joaquín Yarza ${ }^{127}$.

Su propuesta más arriesgada es la reconstrucción del retablo mayor original antes de su sustitución por la fábrica barroca de Gavilán Tomé, principalmente por ciertas contradicciones con lo descrito en el documento número 1801 y por conjeturas poco demostrables referentes a la predela o al remate ${ }^{128}$.

122 J. YARZA LUACES, “Artes del color...”, p. 420.

${ }^{123}$ CH. R. Post, Op. cit., T. III, p. 264.

${ }^{124}$ M. GÓMEZ RASCÓN, Op. cit., pp. 46-47.

${ }^{125}$ A. FRANCO MATA, Op. cit., p. 293.

${ }^{126}$ A. FRANCO MATA, "El Doble Credo en el arte medieval hispánico", Boletín del Museo arqueológico Nacional, XIII, 1-2, (1995), p. 127. La idea también apareció publicada en un suplemento cultural, “Un aspecto iconográfico inédito de Nicolás Francés", Diario de León, Finlandón, 23 de abril de 1995, pp. IV-V.

${ }^{127}$ J. YARZA LUACES, “Artes del color...”, p. 412.

${ }^{128}$ Se expone la teoría en una publicación de carácter divulgativo, A. FRANCO MATA, "Pintura me-
Muy enriquecedora es la aportación de la obra de Víctor Nieto Alcaide, ya que el enfoque que hace del artista se basa en su participación en el trabajo de vidrieras en la sede leonesa ${ }^{129}$, por lo que cualquier paralelismo existente entre el lenguaje formal al que recurre en el campo de lo pictórico y en del trabajo del vidrio, apoyaría de forma contundente las teorías acerca de la procedencia de Maestre Nicolás, al que este autor considera de forma rotunda de origen francés ${ }^{130}$.

Para el autor la principal aportación plástica del artista al arte leonés del siglo XV será la impronta de procedencia parisina derivada del gótico internacional ${ }^{131}$, un lenguaje formal que domina y que transciende de forma fundamental en su obra pictórica.

No existen dudas en esta obra de su participación en la actividad vidriera, de la que no es difícil encontrar apoyos docu-

dieval o el genio de Nicolás Francés", La Catedral de León. Mil años de historia. León, 2002, pp. 150-164. La propuesta fue rebatida en J. YARZA LUACES, "Artes del color...", p. 406.

${ }^{129}$ V. NiETO AlCAIDE, La vidriera española, Madrid, 1998, p. 99. El autor no deja duda de la participación de Nicolás Francés en, no solo, el diseño de cartones para las vidrieras, sino que él mismo las colocaba, es más, le atribuye la labor de su mantenimiento, su reparación y su realización, entre otros trabajos menores, que demuestran su compromiso permanente con la catedral.

${ }^{130}$ Por otro lado no debemos olvidar la gran aportación de los maestros vidrieros franceses coincidiendo con la aparición del gótico internacional, contratados de forma masiva desde cualquiera de los grandes centros artísticos que precisaran sus servicios, durante un periodo fundamental en la historia de la producción vidriera, y que también en León sobre todo el siglo XV supuso un periodo decisivo de intensa actividad en cuanto a la empresa de sus vitrales se refiere, decidiendo completar de forma sistemática el programa de vidrieras iniciado en el siglo XIII. Idem. pp. 98 y 107.

${ }^{131}$ Idem. p. 111, "...las soluciones refinadas de la pintura del internacional parisino de entorno a 1400". 
mentales ${ }^{132}$, si bien el autor discrepa con Gómez Moreno en las atribuciones que se hacen en el Catálogo monumental de 1925. De aquellas rosas de los ventanales de las naves laterales que le fueron atribuidas, descarta la mayor parte, sobre todo debido a la ausencia de amarillo de plata que las caracteriza, inclinándose a pensar que en su mayoría son del siglo XIV. Aunque viendo la irregularidad de estilos que presentan, pudiera ser que se hubiera utilizado algún cartón suyo como diseño de alguna de ellas.

No obstante Víctor Nieto encuentra motivos suficientes para adjudicarle no sólo el diseño, sino también la factura de alguno de los ventanales, basándose en el personalísimo estilo del artista, que se plasma en la forma de aplicar el trazo que acusan sus modelos, como se observa en la segunda capilla del lado norte, concretamente en la cabeza de un peregrino que inconfundiblemente delata la mano de Nicolás Francés.

Su principal consideración como pintor incide en la creación de diseños y cartones. Sin duda su más destacable creación, ya referida, será la que realizó para el tímpano de la puerta de acceso al claustro. En ella puede distinguirse, tal y como explica Víctor Nieto, que si bien el estilo pictórico delata la intervención de Maestre Nicolás, la técnica y el dibujo llevado al vidrio pertenece a otra mano como refiere la documentación, asentada el 26 de febrero de 1454 por el maestro Anequin ${ }^{133}$.

-

${ }^{132}$ Idem, en el documento de 1435 se dice cómo se encarga de "...debojar las vidrieras..", que para el autor no tiene que ser exactamente dibujar cartones. En otro de 1459 se le paga por la colocación de una serie de nueve cristales en la capilla de San Sebastián.

${ }^{133}$ Acerca de la documentación de la vidriera véase, W. MERINO RUBIO, Arquitectura hispano flamenca, León, 1995, p. 328.

\section{CONCLUSIÓN}

Llegados aquí podemos reconocer la falta de un estudio actualizado de todo lo que aún se conserva y de la consideración de aquello que puede atribuirse a discípulos y seguidores que darían a conocer el verdadero alcance de este artista, quien a todas luces parece haber aportado suficiente genialidad para que sus recursos se perpetuaran adaptados a la nueva estética flamenca, obligando a una reconsideración de todos aquellos aspectos, suficientes para proceder a un estudio en profundidad de la figura del artista.

Los avatares sufridos por la obra del artista suponen un obstáculo para un estudio integral, que es ligeramente paliado por el ingente trabajo realizado por aquellos primeros investigadores de la primera mitad del siglo XX que documentaron algunas de las obras perdidas y que hoy pueden servir para completar parcialmente el conjunto. Por ello es importante destacar la acertada adquisición de la pequeña tabla de Santa Escolástica para el Museo Provincial de León, que muy probablemente fue la que vio Chanlder Post en su visita al taller de Torbado, y que formaría parte del expoliado retablo mayor de la Catedral de León, que por sus particulares dimensiones suscita una composición aun más complicada del aparato original, que poseería tablas de muy distintos tamaños para la representación del nutrido grupo de santos que acompañaban a los episodios principales.

Por otro lado, se echa en falta un análisis en profundidad de lo que a su labor como muralista se refiere, teniendo en cuenta que muchos de los estudiosos que se han ocupado de este artista reconocen en estos encargos su principal relevancia, destacando sobre todos ellos su trabajo en los muros del claustro, pese a que el tiempo no ha sido lo clemente que hubiera sido de desear con la obra. 
En lo que se refiere a la técnica pictórica del maestro, pocos han sido los autores que han abordado este tema, sobre todo en lo que atañe a su obra mural. Tan solo y con ocasión de la intervención de los murales del claustro y tras los análisis pertinentes, la empresa restauradora la describió como un temple a base de un ligante proteico como aglutinante sobre soporte en seco de cal y yeso, con una carga de árido fino y un añadido de fibra vegetal como arriccio y otra capa fina de estuco ligado con cola animal como intonaco ${ }^{134}$. Los pigmentos serían de una calidad inusual para este tipo de obras con revela el uso de verde esmeralda obtenido a partir de malaquita ${ }^{135}$.

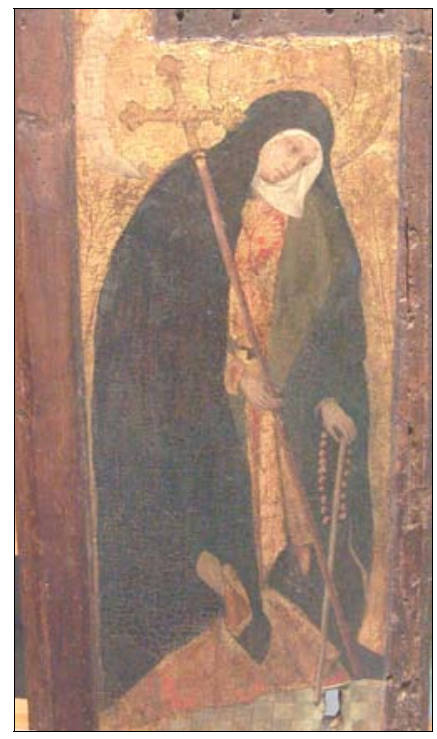

- Lám. 1. Santa Escolástica.

Tabla probablemente procedente del retablo mayor original de la Catedral de León. Museo de León

-

${ }^{134}$ P. L. YAGÜE HOYAL, “Historia de la restauración de las pinturas murales del claustro de la catedral de León", Restauración de las pinturas murales del claustro de la catedral de León, Valladolid, 1997, pp. 59-67.

${ }^{135}$ El uso de malaquita es material muy inusual en este tipo de obras que José María Cabrera reconoce ver utilizado en el claustro leonés por primera vez en España, Idem, p. 63.
Desde nuestra perspectiva actual debemos intentar trascender de su personalidad concreta para abarcar, mediante las conclusiones de su análisis, de un modo más general el entorno en el que se desarrolla su labor, más cuando como en este caso, ese artista significa tanto en ese momento y en ese lugar. La figura de Maese Nicolás Francés entraña muchas de las claves del panorama pictórico leonés durante gran parte del siglo $\mathrm{XV}$, conocerle implica la comprensión de las fórmulas plásticas que fundamentaron aquel arte.

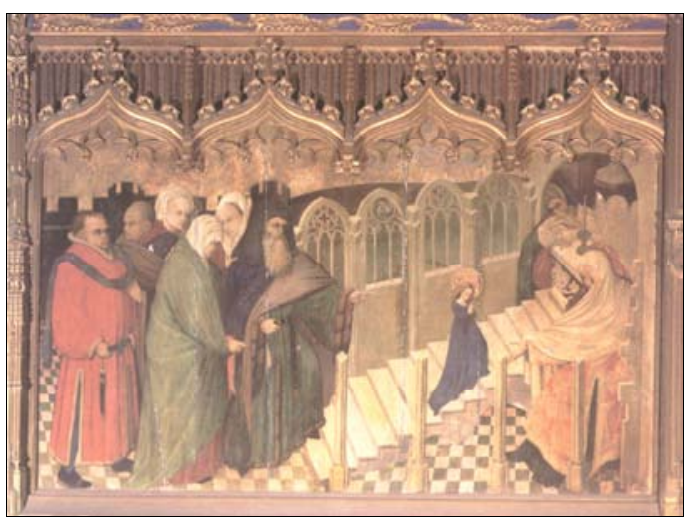

- Lám. 2. Presentación de María en el templo. Retablo mayor de la Catedral de León.

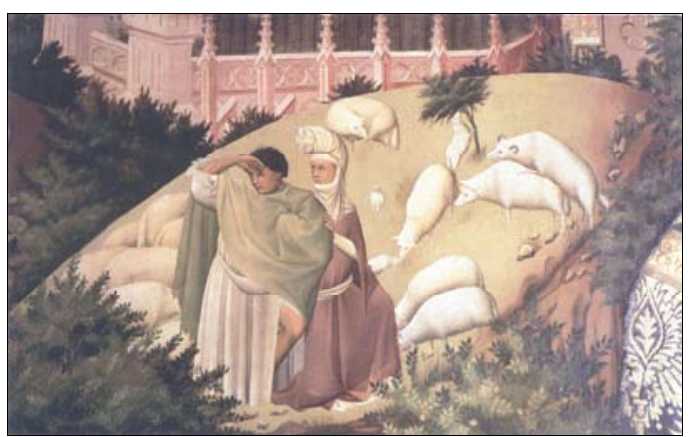

- Lám. 3. Traslado del cuerpo de Santiago. Detalle. Retablo mayor de la Catedral de León. 


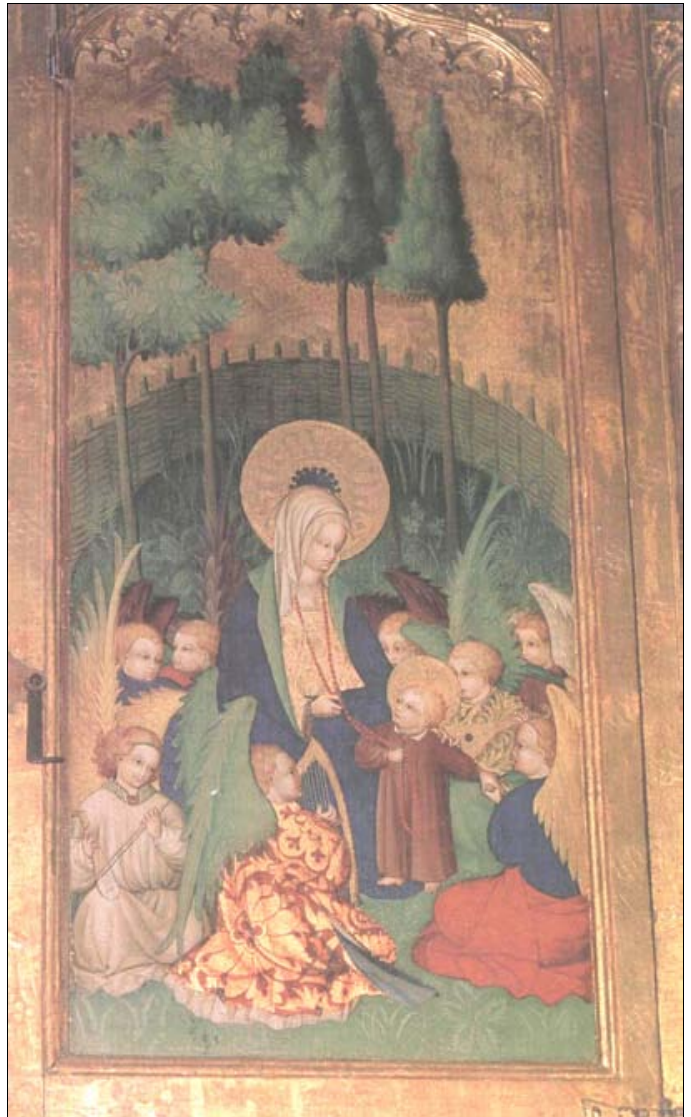

- Lám. 4. Hortus conclusus. Retablo de la capilla del Contador Saldaña. Convento de Santa Clara de Tordesillas (Valladolid).

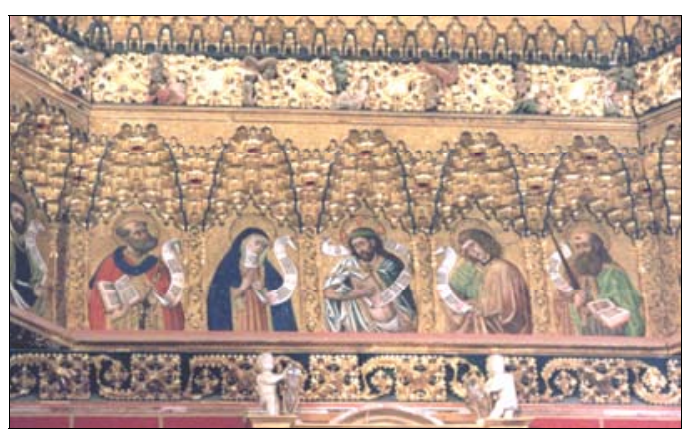

- Lám. 6. Friso bajo el arrocabe de la Capilla Mayor de la iglesia del convento de Santa Clara de Todesillas (Tordesillas). Detalle.

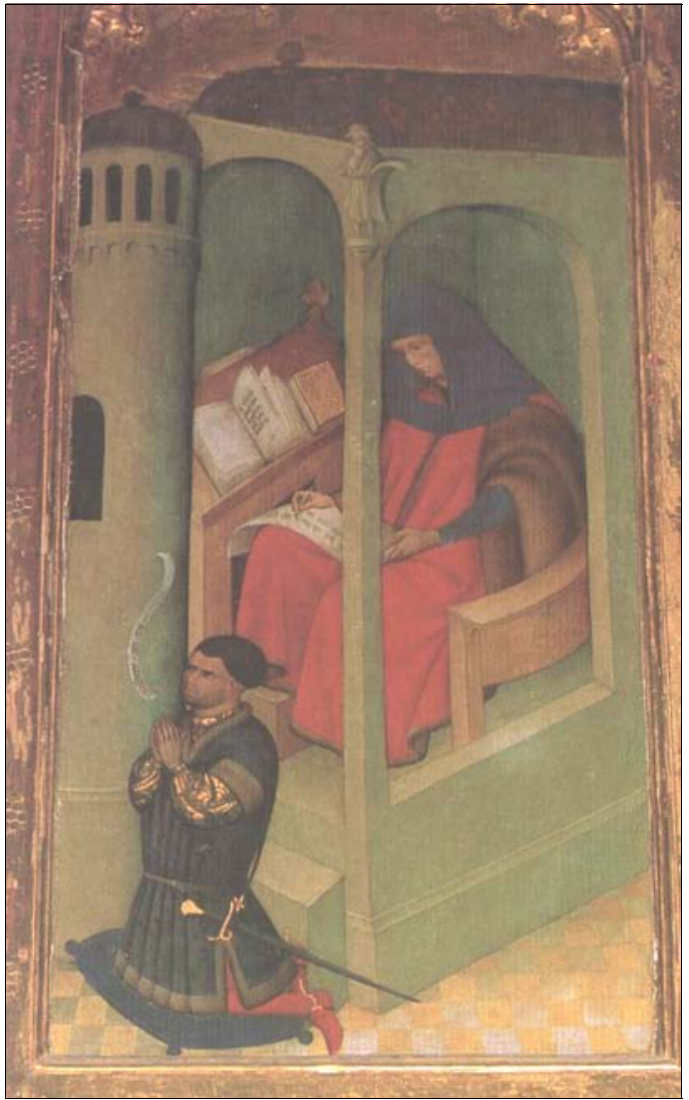

- Lám. 5. Evangelista con el Contador Saldaña en actitud de donante. Retablo de la capilla del Contador Saldaña. Convento de Santa Clara de Tordesillas (Valladolid).

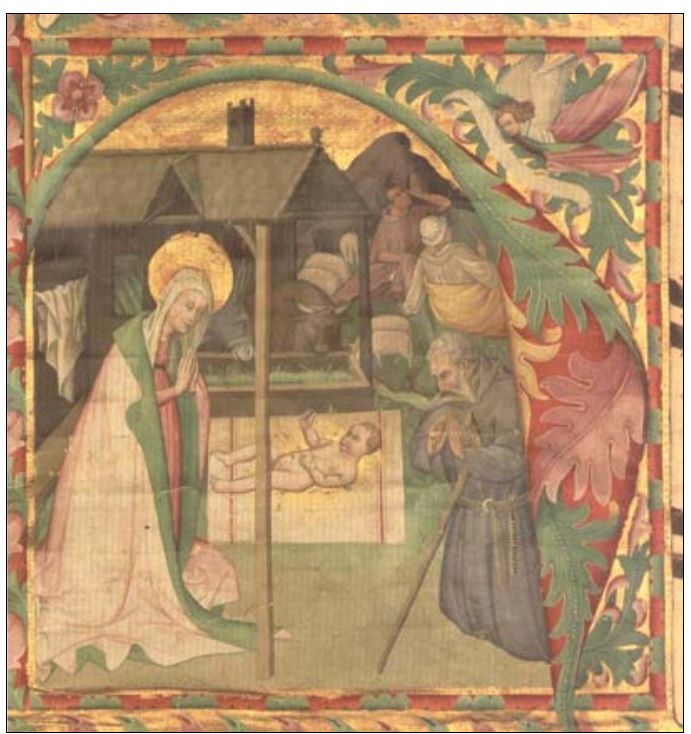

- Lám. 7. Natividad. Libro de coro. Biblioteca de la Real Colegiata de San Isidoro de León. 


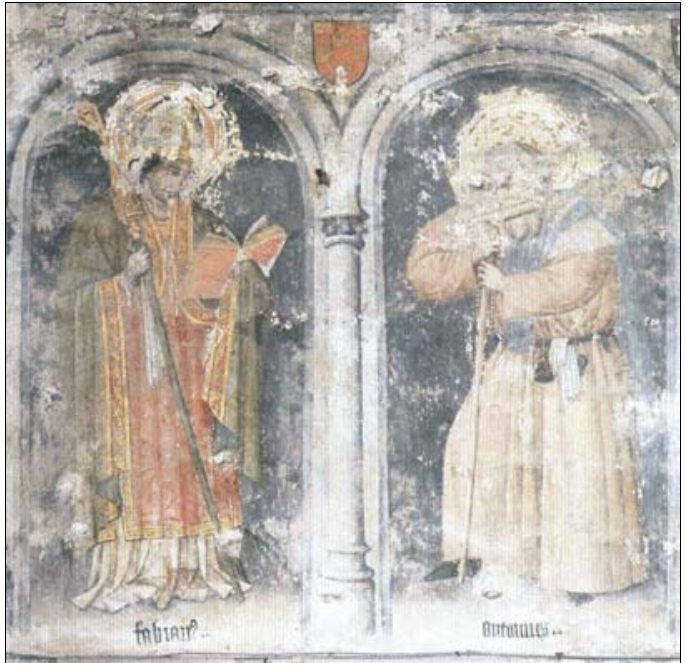

- Lám. 8. San Fabián y San Antonio. Pintura mural. Antigua capilla de San Sebastián, actualmente capilla de Santa Teresa. Catedral de León.

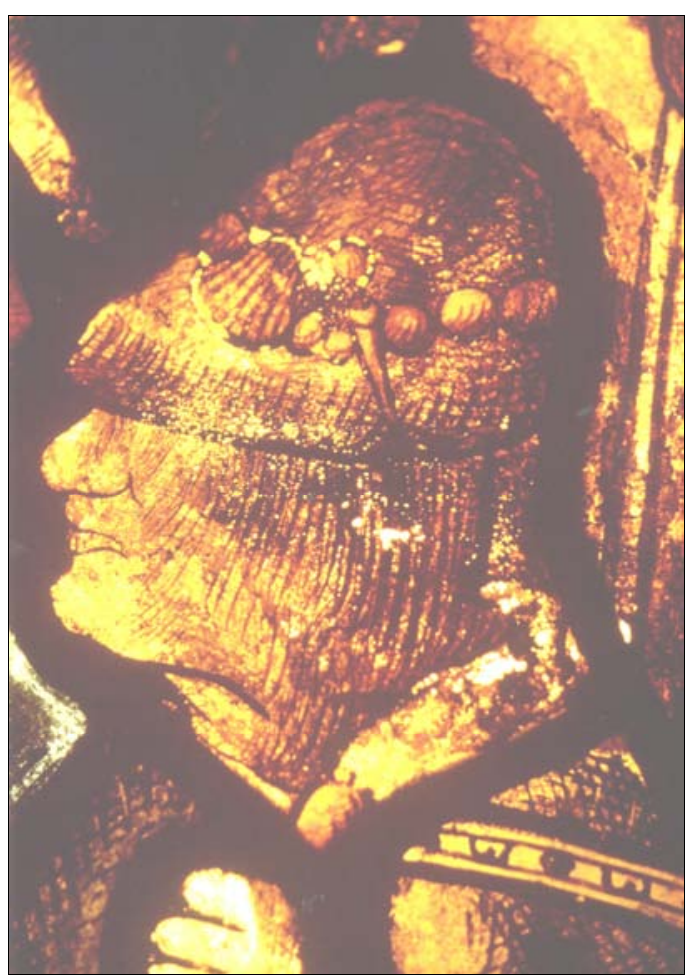

- Lám. 10. Vidriera de la segunda capilla del lado norte de la Catedral de León. Detalle.

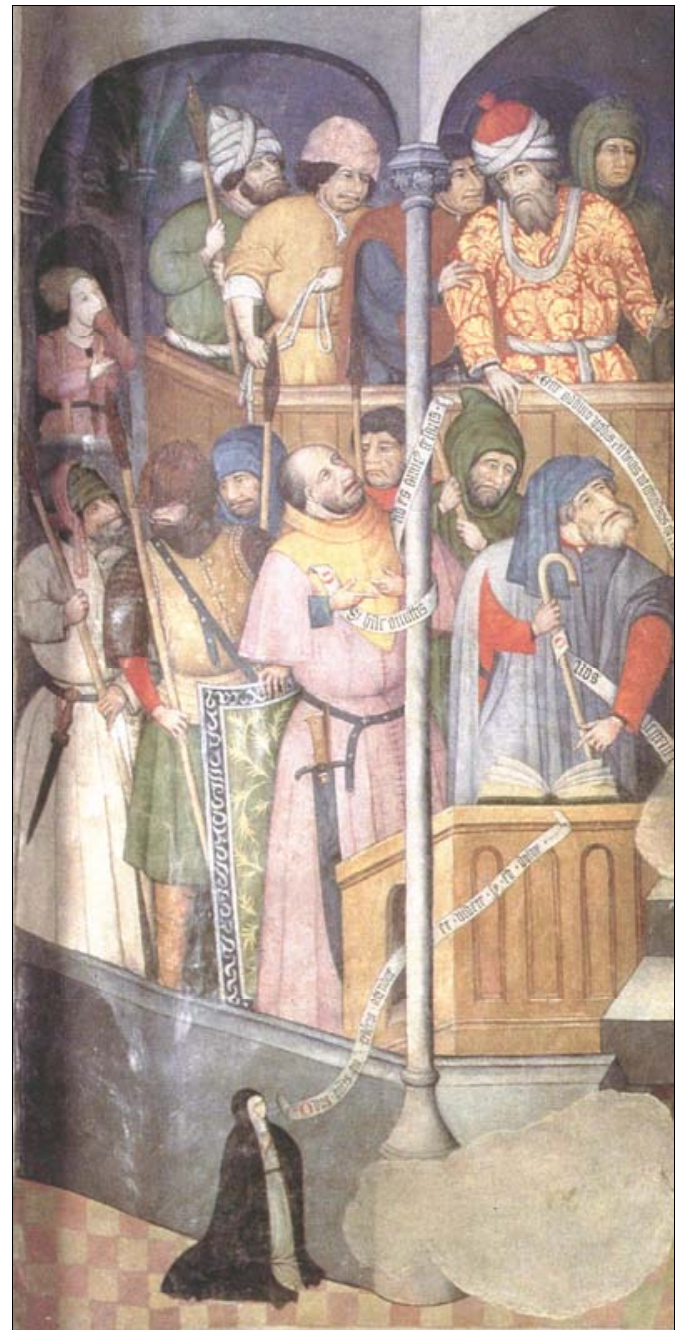

- Lám. 11. Ecce Homo. Pintura mural. Girola de la Catedral de León.

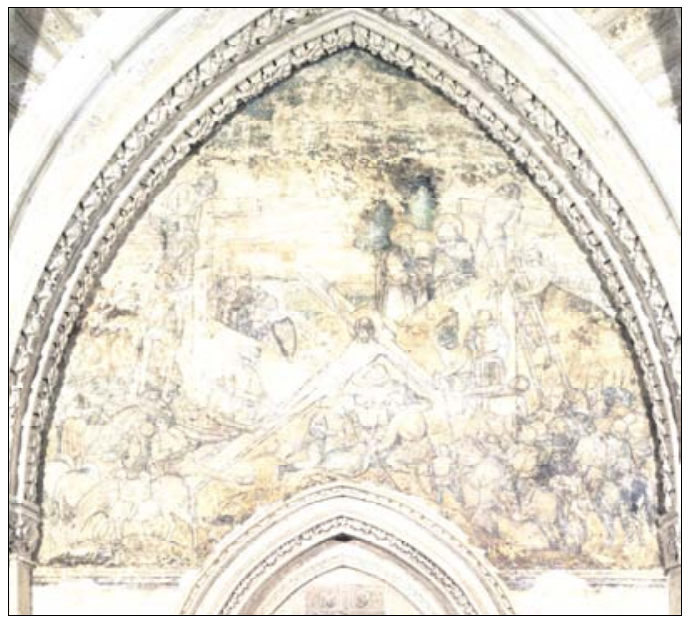

- Lám. 12. El Enclavamiento. Pintura mural. Tímpano del claustro de la Catedral de León. 